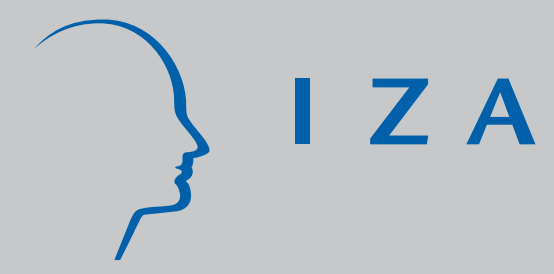

IZA DP No. 2468

Designing Optimal Taxes with a Microeconometric Model of Household Labour Supply

Rolf Aaberge

Ugo Colombino

November 2006 


\title{
Designing Optimal Taxes with a Microeconometric Model of Household Labour Supply
}

\author{
Rolf Aaberge \\ Statistics Norway \\ and IZA Bonn
}

Ugo Colombino

University of Turin

and Statistics Norway

\section{Discussion Paper No. 2468 \\ November 2006}

\author{
IZA \\ P.O. Box 7240 \\ 53072 Bonn \\ Germany \\ Phone: +49-228-3894-0 \\ Fax: +49-228-3894-180 \\ E-mail: iza@iza.org
}

Any opinions expressed here are those of the author(s) and not those of the institute. Research disseminated by IZA may include views on policy, but the institute itself takes no institutional policy positions.

The Institute for the Study of Labor (IZA) in Bonn is a local and virtual international research center and a place of communication between science, politics and business. IZA is an independent nonprofit company supported by Deutsche Post World Net. The center is associated with the University of Bonn and offers a stimulating research environment through its research networks, research support, and visitors and doctoral programs. IZA engages in (i) original and internationally competitive research in all fields of labor economics, (ii) development of policy concepts, and (iii) dissemination of research results and concepts to the interested public.

IZA Discussion Papers often represent preliminary work and are circulated to encourage discussion. Citation of such a paper should account for its provisional character. A revised version may be available directly from the author. 


\section{ABSTRACT}

\section{Designing Optimal Taxes with a Microeconometric Model of Household Labour Supply*}

The purpose of this paper is to present an exercise where we identify optimal income tax rules under the constraint of fixed tax revenue. To this end, we estimate a microeconomic model with 78 parameters that capture heterogeneity in consumption-leisure preferences for singles and couples as well as in job opportunities across individuals based on detailed Norwegian household data for 1994. For any given tax rule, the estimated model can be used to simulate the choices made by single individuals and couples. Those choices are therefore generated by preferences and opportunities that vary across the decision units. Differently from what is common in the literature, we do not rely on a priori theoretical optimal taxation results, but instead we identify optimal tax rules - within a class of 6-parameter piece-wise linear rules - by iteratively running the model until a given social welfare function attains its maximum under the constraint of keeping constant the total net tax revenue. We explore a variety of social welfare functions with differing degree of inequality aversion and also two alternative social welfare principles, namely equality of outcome and equality of opportunity. All the social welfare functions turn out to imply an average tax rate lower than the current 1994 one. Moreover, all the optimal rules imply - with respect to the current rule - lower marginal rates on low and/or average income levels and higher marginal rates on relatively high income levels. These results are partially at odds with the tax reforms that took place in many countries during the last decades. While those reforms embodied the idea of lowering average tax rates, the way to implement it has typically consisted in reducing the top marginal rates. Our results instead suggest to lower average tax rates by reducing marginal rates on low and average income levels and increasing marginal rates on very high income levels.

JEL Classification: $\quad \mathrm{H} 21, \mathrm{H} 31, \mathrm{~J} 22$

Keywords: labour supply, optimal taxation, random utility model, microsimulation

Corresponding author:

Rolf Aaberge

Research Department

Statistics Norway

P.O. Box 8131 Dep.

$\mathrm{N}-0033$ Oslo

Norway

E-mail: rolf.aaberge@ssb.no

\footnotetext{
* We would like to thank Tom Wennemo for skilful programming assistance, Anne Skoglund for editing the paper and Terje Skjerpen for careful proofreading. The Norwegian Research Council, the Italian Ministry of University and Research and the Compagnia di San Paolo has provided financial support for this project. Parts of this paper were written when Rolf Aaberge was visiting ICER in Torino. ICER is gratefully acknowledged for providing financial support and excellent working conditions.
} 


\section{Introduction}

This paper presents an empirical analysis of optimal taxation. The purpose is not new, but the exercise illustrated here differs in many important ways from previous attempts to empirically compute optimal taxes. The standard procedure adopted in the literature starts with some version of the optimal taxation framework originally set up in the seminal paper by Mirlees (1971). The next step typically consists of feeding with numbers - taken from some previous empirical analysis - the formulas produced by the theory. This literature is surveyed by Tuomala (1990). A recent strand of research adopts the same approach to address the inverse optimal taxation problem, i.e. retrieving the social welfare function that makes optimal a given tax rule (Bourguignon and Spadaro, 2005). There are two main problems with this literature: 1) the theoretical results become amenable to an operational interpretation only by adopting some special assumptions concerning the preferences, the composition of the population and the structure of the tax rule; 2) the empirical measures used as counterparts of the theoretical concepts are usually derived from previous estimates obtained under assumptions that may be different from those used in the theoretical model. As a consequence the consistency between the theoretical model and the empirical measures is dubious and the significance of the numerical results remains uncertain. An important contribution by Saez (2001) makes Mirlees' results more easily operational by reformulating them in terms of labour (or income) supply elasticities in order to provide a more direct link between theoretical results and empirical measures. Also, a recent paper by Laroque (2005) departs substantially from the Mirlees' tradition and proposes a simpler framework that focuses upon the determination of the Laffer bound (the tax rate that maximizes the tax revenue). Although these new contributions are interesting and useful in easing the empirical implementation of theoretical results, they might still suffer from a possible inconsistency between the theoretical model and the empirical measures used to implement the models. As main remaining limitations of this literature we may mention: (a) the agent is the individual and simultaneous household decisions are ignored; (b) quantity constraints and limitations on the choice of hours of work are ignored; (c) participation decisions and hours decisions are typically not simultaneously accounted for: either the hours decision (as in Mirlees 1971) or the participation decision (as in Diamond 1980) is modelled. ${ }^{1}$

Although those limitations and other restrictive assumptions may be overcome in the future, we follow here a completely different approach. We do not start from theoretical results dictating conditions for optimal tax rules under various assumptions. Instead we use a microeconometric model of labour supply in order to identify by simulation the tax rule that maximizes a social welfare

\footnotetext{
${ }^{1}$ A notable exception is Saez (2002) where both participation and hour's decisions are combined using some rather restrictive simplifying assumptions. An interesting empirical application of Saez's model is provided by Blundell et al. (2006).
} 
function. The microeconometric simulation approach is common in evaluating tax reforms, but has not been much used in empirical optimal taxation studies. ${ }^{2}$ The closest previous example adopting a similar approach is probably represented by Fortin, Truchon and Beauséjour (1993), who however use a calibrated (not estimated) model with rather restrictive (Stone-Geary) preferences and focus on alternative income support schemes rather than on the whole tax rule. We develop a microeconometric model of labour supply that allows for a rather flexible representation of preferences, embodies an exact representation of taxes and transfers, represents simultaneous decisions of household members and accounts for quantity constraints on labour supply choices.

The microeconometric model is briefly presented in Section 2. In the Appendix we present the empirical specification of the utility functions and the choice sets and we provide the estimation results based on Norwegian data. The main behavioural implications of the estimates are illustrated by the labour supply elasticities in Section 3. Once estimated, the model can be run to simulate choices and individual welfare levels for a sample of households given any particular tax rule. However, since preferences are heterogeneous and some individuals live as singles whereas others form families and live together it does not make sense to treat the estimated utility functions as comparable individual welfare functions. Thus, it is required to introduce measures of individual welfare that justify interpersonal comparisons. Section 4.1 explains the procedure we follow to circumvent the problem.

As explained in Section 4.2, aggregation of welfare levels across individual is made by using members from a class of rank-dependent social welfare functions with varying degree of inequalityaversion and relying on two alternative social welfare criteria; Equality of Opportunity (EOp) and the more traditional Equality of Outcome (EO). The latter consists in maximizing a weighted sum of individual welfare levels. The former is a computable concept of equality of opportunity developed by Roemer (1998). The idea motivating the development of this new criterion is that "outcomes" are the joint result of "opportunities" and "effort", and that the social planner might wish to account for the inequality due to unequal "opportunities" but not for the inequality due to unequal "effort". In a previous contribution that originated from an international research project (Roemer et al. 2003), this concept has been applied to evaluate the EOp performance of income tax rules in various countries, using a relatively simple common model of labour supply behaviour with calibrated parameters. Under this respect, this paper extends the previous study in several respects. First, in order to allow for alternative weighting profiles in the treatment of income differentials that arise from factors beyond the individuals' control, a generalized version of Roemer's (1998) EOp-criterion is introduced. Secondly, we employ a relatively sophisticated model of labour supply that provides a simultaneous treatment of partners' decisions and accounts for quantity constraints on the distribution of hours.

\footnotetext{
${ }^{2}$ A recent survey of microsimulation analyses of tax system is provided by Bourguignon and Spadaro (2006).
} 
Finally, while the previous study only concerned male heads of household's 25-40 years old this study deals with approximately the entire labour force.

Finally, we identify optimal tax rules - within a class of 6-parameter piece-wise linear rules by iteratively running the model until the social welfare function is maximized under the constraint of keeping constant the total net tax revenue. The resulting optimal tax rules are presented in Section 5. Section 6 contains the final comments.

\section{The microeconometric labour supply model}

The labour supply model used in this study is detailed described in Appendix A. Here we give a birdeye presentation. The model can be considered as an extension of the standard multinomial logit model, and differs from the traditional models of labour supply in several respects. ${ }^{3}$ First, it accounts for observed as well as unobserved heterogeneity in tastes and choice constraints, which means that it is able to take into account the presence of quantity constraints in the market. Second, it includes both single person households and married or cohabiting couples making joint labour supply decisions. A proper model of the interaction between spouses in their labour supply decisions is important as most of the individuals are married or cohabiting. Third, by taking all details in the tax system into account the budget sets become complex and non-convex in certain intervals.

For expository simplicity we consider in this section only the behaviour of a single person household. In the model, agents choose among jobs characterized by the wage rate $w$, hours of work $h$ and other characteristics. The problem solved by the agent looks like the following:

$$
\max _{(w, h, j) \in B} U(c, h, j, \varepsilon)
$$

subject to the budget constraint $c=f(w h, I)$, where $h$ denotes hours of work, $w$ is the pre-tax wage rate, $j$ and $\varepsilon$ indicate respectively other observed and unobserved job and/or household characteristics, $I$ is the pre-tax non-labour income (exogenous), $c$ is disposable income, $f$ represents the tax rule that transforms pre-tax incomes ( $w h, I)$ into net income $c, B$ denotes the set of all opportunities available to the household (including non-market opportunities, i.e. a "job" with $w=0$ and $h=0)$.

\footnotetext{
${ }^{3}$ Examples of previous applications of this approach are found in Aaberge, Dagsvik and Strøm (1995), and Aaberge, Colombino and Strøm $(1999,2000)$. The modeling approach used in these studies differs from the standard labour supply models by characterizing behaviour in terms of a comparison between utility levels rather than between marginal variations of utility. These models are close to other recent contributions adopting a discrete choice approach such as Dickens and Lundberg (1993) and Euwals and van Soest (1999).
} 
Agents can differ not only in their preferences and in their wage (as in the traditional model) but also in the number of available jobs of different type. Moreover, for the same agent, wage rates (unlike in the traditional model) can differ from job to job. As analysts we observe the chosen $h$ and $w$, but we do not know exactly what opportunities are contained in $B$. Therefore we use a probability density function to represent $B$. Let $p(h, w, j)$ denote the density of jobs of type $(h, w, j)$. By specifying a probability density function on $B$ we can for example allow for the fact that jobs with hours of work in a certain range are more or less likely to be found, possibly depending on agents' characteristics; or for the fact that for different agents the relative number of market opportunities may differ. We assume that the utility function can be factorised as

$$
U(f(w h, I), h, j, \mathcal{E})=v(f(w h, I), h, j) \mathcal{E},
$$

where $v$ and $\varepsilon$ are the systematic and the stochastic component, respectively. Moreover, we assume that $\varepsilon$ is i.i.d. according to:

$$
\operatorname{Pr}(\varepsilon \leq u)=\exp \left(-u^{-1}\right)
$$

We observe the chosen $h, w$ and $j$. Therefore we can specify the probability that the agent chooses a job with observed characteristics $(h, w, j)$. Let $B(w, h, j) \subset B$ denote the subset of feasible jobs with hours $h$, wage rate $w$ and other observable job attributes $j$. The term $\varepsilon$ is a random taste-shifter that accounts for the effect on utility of all the characteristics of the household-job match observed by the household but not by us. It can be shown that under the assumptions (2.1), (2.2) and (2.3) we can write the probability density function of a choice $(h, w, j)$ as ${ }^{4}$

$$
\varphi(h, w, j) \equiv \operatorname{Pr}\left[U(f(w h, I), h, j)=\max _{(x, y, z) \in B} U(f(x y, I), y, z)\right]=\frac{v(f(w h, I), h, j) p(h, w, j)}{\iiint_{B} v(f(x y, I), y, z) p(x, y) d x d y d z}
$$

where $p(h, w, j)$ is the density of choice opportunities which can be interpreted as the relative frequency (in the choice set B) of job opportunities of type $(h, w, j$ ). Opportunities with $h=0$ (and $w=0$ ) are non-market opportunities (i.e. alternative allocations of "leisure"). The density (2.4) is the contribution of an observation $(h, w, j)$ to the likelihood function, which is then maximized in order to estimate the parameters of $v(f(w h, I), h, j)$ and of $p(h, w, j)$.

\footnotetext{
${ }^{4}$ For the derivation of the choice density (2.4), see Aaberge et al. (1999). Note that (2.4) can be considered as a special case of the more general multinomial type of framework introduced by Ben-Akiva and Watanatada (1981) and Dagsvik (1994)..
} 
The intuition behind expression (2.4) is that the probability of a choice $(h, w, j)$ can be expressed as the relative attractiveness - weighted by a measure of "availability" $p(h, w, j)$ - of jobs of type $(h, w, j)$.

It is important to stress that household member choose among jobs (characterized by $h, w$ and other factors $j$ ), not just among different values of $h$. Theoretical optimal taxation models typically consider effort as the agents' choice variable. Effort does not coincide with hours of work; it might include searching for jobs of better quality etc. On the other hand, empirical models of labour supply used for tax reform evaluations have traditionally considered hours of work as the sole choice variable, implicitly equating hours of work and effort. Exceptions are provided by Bourguignon and Spadaro (2005) and by Bargain (2006), who under rather special assumptions are able to impute to each agent an effort value. In our model we do not strictly identify effort and hours of work, since the agent chooses a package that includes not only hours but also wage rates and other job characteristics.

As explained in Appendix A, the model contains 78 parameters that capture the heterogeneity in preferences and opportunities among households and individuals. This version of the model is used to simulate the choices given a particular tax rule. Those choices are therefore generated by preferences and opportunities that vary across the decision units. For the purpose of welfare evaluation, however, we also estimate a common utility function where we account for differences in availability of job opportunities. It is this common utility function that is used to compute and compare the individual welfare levels that will form the basis of the social welfare evaluation of tax reforms. The estimates of the common utility function are given in Section 4.

\section{Labour supply elasticities}

In this section we report wage and income elasticities of labour supply both to illustrate the behavioural implications of the microeconometric model and because they are useful for the understanding and the interpretation of the optimal taxation results that will be presented in Section 6 .

The wage elasticities are computed by means of stochastic simulation. Wage rates are incremented by $1 \%$. Draws are made from the distributions related to preferences and opportunities. Given the responses of each individual, we aggregate them to compute the aggregate elasticities. Tables 3.1 and 3.2 display these elasticities. Since many individuals in this labour supply model of discrete choice will not react to small exogenous changes, the elasticities in Tables 3.1 and 3.2 have been computed as an average of the percentage changes in labour supply from a 10 percent increase in the wage rates. 
Table 3.1. Labour supply elasticities with respect to wage for single females, single males, married females and married males by deciles of household disposable income* Norway 1994

\begin{tabular}{|c|c|c|c|c|c|c|}
\hline \multirow[b]{2}{*}{ Family status } & \multirow[b]{2}{*}{ Type of elasticity } & \multirow[b]{2}{*}{$\begin{array}{c}\text { Household } \\
\text { Income } \\
\text { decile }\end{array}$} & \multicolumn{2}{|c|}{ Female elasticities } & \multicolumn{2}{|c|}{ Male elasticities } \\
\hline & & & $\begin{array}{l}\text { Own wage } \\
\text { elasticities }\end{array}$ & $\begin{array}{c}\text { Cross } \\
\text { elasticities }\end{array}$ & $\begin{array}{l}\text { Own wage } \\
\text { elasticities }\end{array}$ & $\begin{array}{c}\text { Cross } \\
\text { elasticities }\end{array}$ \\
\hline \multirow{15}{*}{$\begin{array}{l}\text { Single females and } \\
\text { males }\end{array}$} & \multirow{5}{*}{$\begin{array}{l}\text { Elasticity of the } \\
\text { probability of } \\
\text { participation }\end{array}$} & I & 0.59 & & 0.00 & \\
\hline & & II & 0.45 & & 0.00 & \\
\hline & & III-VII & 0.06 & & 0.06 & \\
\hline & & IV & 0.00 & & 0.00 & \\
\hline & & $\mathrm{X}$ & 0.00 & & 0.00 & \\
\hline & \multirow{5}{*}{$\begin{array}{l}\text { Elasticity of the } \\
\text { conditional expectation } \\
\text { of total supply of hours }\end{array}$} & I & -0.17 & & 0.77 & \\
\hline & & II & -0.04 & & 0.00 & \\
\hline & & III-VII & -0.08 & & -0.08 & \\
\hline & & IV & -0.07 & & 0.00 & \\
\hline & & $\mathrm{X}$ & 0.00 & & 0.00 & \\
\hline & \multirow{5}{*}{$\begin{array}{l}\text { Elasticity of the } \\
\text { unconditional } \\
\text { expectation of total } \\
\text { supply of hours }\end{array}$} & I & 0.42 & & 0.77 & \\
\hline & & II & 0.42 & & 0.00 & \\
\hline & & III-VII & -0.02 & & -0.02 & \\
\hline & & IV & -0.07 & & 0.00 & \\
\hline & & $\mathrm{X}$ & 0.00 & & 0.00 & \\
\hline \multirow{15}{*}{$\begin{array}{l}\text { Married/cohabitating } \\
\text { females and males }\end{array}$} & \multirow{5}{*}{$\begin{array}{l}\text { Elasticity of the } \\
\text { probability of } \\
\text { participation }\end{array}$} & I & 1.03 & -0.28 & 0.90 & -0.23 \\
\hline & & II & 0.35 & -0.14 & 0.79 & 0.00 \\
\hline & & III-VII & 0.14 & -0.23 & 0.13 & -0.10 \\
\hline & & IV & 0.12 & -0.12 & 0.06 & -0.06 \\
\hline & & $\mathrm{X}$ & 0.07 & 0.00 & 0.06 & -0.19 \\
\hline & \multirow{5}{*}{$\begin{array}{l}\text { Elasticity of the } \\
\text { conditional expectation } \\
\text { of total supply of hours }\end{array}$} & I & 1.51 & -0.01 & 0.87 & 0.11 \\
\hline & & II & 0.62 & -0.53 & 0.38 & -0.08 \\
\hline & & III-VII & 0.27 & -0.24 & 0.18 & -0.14 \\
\hline & & IV & 0.08 & -0.22 & 0.02 & -0.09 \\
\hline & & $\mathrm{X}$ & 0.19 & -0.10 & -0.02 & -0.23 \\
\hline & \multirow{5}{*}{$\begin{array}{l}\text { Elasticity of the } \\
\text { unconditional } \\
\text { expectation of total } \\
\text { supply of hours }\end{array}$} & $\mathrm{I}$ & 2.54 & -0.29 & 1.77 & -0.12 \\
\hline & & II & 0.97 & -0.67 & 1.17 & -0.08 \\
\hline & & III-VII & 0.41 & -0.47 & 0.31 & -0.24 \\
\hline & & IV & 0.20 & -0.34 & 0.08 & -0.14 \\
\hline & & $X$ & 0.26 & -0.10 & 0.05 & -0.42 \\
\hline
\end{tabular}


The third and the sixth panel of Table 3.1 and third and sixth column of Table 3.2 give the unconditional elasticities of labour supply, which means that both the impact on participation and hours supplied is accounted for.

Table 3.1 demonstrates that all own wage elasticities of married females and married males (except for the upper decile) are positive, whereas single females and males located in the central part of the income distribution will respond weakly negative to a wage increase. Second, we observe that almost all cross wage elasticities are negative due to the income effect. Thus, an increase in, say, the wage rate for males implies that the labour supply of his spouse goes down. The negative cross wage elasticities means that an overall wage increase give far weaker impact on labour supply, both for males and females, than partial wage increase for the two gender. For couples belonging to the ninth decile of the couples' income distribution this counteracting effect is so strong that labour supply of these couples's declines from an overall wage increase. From the first two rows in each of the panels of Table 3.1 we observe that the labour supply of the 10-20 percent poorest are far more responsive to changes in economic incentives than the 10-20 percent richest. For single females and males in the 3-8 deciles of their corresponding income distributions we observe backward bending labour supply curves as income effects dominate over substitution effects. By comparing the fourth and fifth panel of Table 3.1 we see for married/cohabitating females that hours supplied (given participation), in particular for those belonging to the poorest couples, is by far more responsive than participation. This result is a reflection of the flexibility of the Norwegian labour market, where jobs with part-time working hours are rather common. Moreover, rather generous maternity leave arrangements and high coverage of and subsidized kindergartens makes it is attractive for women to combine the raising of children and participation in labour market activities. By contrast, for single females we find that participation increases when wages increase, whereas hours supplied (given participation) decrease. A similar, but weaker, effect is found for single males with medium high incomes. 
Table 3.2. Aggregate labour supply elasticities with respect to wage for single and married individuals. Norway 1994

\begin{tabular}{lccccc}
\hline \multirow{2}{*}{$\begin{array}{l}\text { Family } \\
\text { status }\end{array}$} & Type of elasticity & \multicolumn{2}{c}{ Female elasticities } & \multicolumn{2}{c}{ Male elasticities } \\
\cline { 3 - 5 } & $\begin{array}{c}\text { Own wage } \\
\text { elasticities }\end{array}$ & $\begin{array}{c}\text { Cross } \\
\text { elasticities }\end{array}$ & $\begin{array}{c}\text { Own wage } \\
\text { elasticities }\end{array}$ & $\begin{array}{c}\text { Cross } \\
\text { elasticities }\end{array}$ \\
\hline $\begin{array}{l}\text { Elasticity of the probability of } \\
\text { participation }\end{array}$ & 0.12 & & 0.04 & \\
$\begin{array}{l}\text { Single } \\
\text { females } \\
\text { and males }\end{array}$ & $\begin{array}{c}\text { Elasticity of the conditional } \\
\text { expectation of total supply of } \\
\text { hours }\end{array}$ & -0.09 & & -0.02 & \\
& $\begin{array}{c}\text { Elasticity of the unconditional } \\
\text { expectation of total supply of } \\
\text { hours }\end{array}$ & 0.02 & & 0.02 & -0.11 \\
\hline $\begin{array}{c}\text { Elasticity of the probability of } \\
\text { participation }\end{array}$ & 0.21 & -0.19 & 0.23 & -0.13 \\
$\begin{array}{l}\text { Married } \\
\text { females } \\
\text { and males }\end{array}$ & $\begin{array}{c}\text { Elasticity of the conditional } \\
\text { expectation of total supply of } \\
\text { hours }\end{array}$ & 0.31 & -0.23 & 0.16 & -0.23 \\
\hline $\begin{array}{c}\text { Elasticity of the unconditional } \\
\text { expectation of total supply of } \\
\text { hours }\end{array}$ & 0.52 & -0.42 & 0.39 & \\
\hline
\end{tabular}

The major feature of the estimated labour supply elasticities can be summarized as follows: (a) labour supply of married women is far more elastic than for married men; (b) individuals belonging to lowincome households are much more elastic than individuals belonging to high-income households. As demonstrated by the review of Røed and Strøm (2002) these findings are consistent with the findings in many recent studies. The sharp decline in elasticities with respect to income suggests that marginal tax rates on low and average income should be reduced, which is in conflict with the widespread opinion that - at least for efficiency purposes - the marginal tax rate profile on personal income should be flattened and the tax rates on higher incomes should be reduced. However, the design of an optimal system will of course depend on the trade-off between efficiency and equality exhibited by the chosen social welfare function and will be further discussed in the next sections.

To complement the information provided by the wage elasticities Tables 3.3 and 3.4 display information for income elasticities. Non-labour income comprises several income categories, which are unevenly distributed among households and do not change uniformly in our simulation experiments. Since the income elasticities are household-specific, the aggregate labour supply response to a shift that involves changes in non-labour income, is the result of a complex calculation. The simulations with respect to capital income and cash transfers are unevenly affected by the general economic growth and the tax rate adjustments. Table 3.4 shows how the elasticity of labour supply 
with respect to changes in these income categories depends on gender, household type and location in the income distribution.

Table. 3.3. Labour supply elasticities with respect to non-labour income for single females, single males, married females and married males by deciles of household disposable income. Norway 1994

\begin{tabular}{|c|c|c|c|c|c|c|c|c|}
\hline \multirow[b]{2}{*}{ Family status } & \multirow[b]{2}{*}{ Type of elasticity } & \multirow[b]{2}{*}{$\begin{array}{l}\text { Household } \\
\text { Income } \\
\text { decile }\end{array}$} & \multicolumn{3}{|c|}{ Female elasticities } & \multicolumn{3}{|c|}{ Male elasticities } \\
\hline & & & $\begin{array}{c}\text { Non-labour } \\
\text { income (cap. } \\
\text { income + cash } \\
\text { transfers) }\end{array}$ & $\begin{array}{l}\text { Capital } \\
\text { income }\end{array}$ & $\begin{array}{l}\text { Cash } \\
\text { trans- } \\
\text { fers }\end{array}$ & $\begin{array}{c}\text { Non-labour } \\
\text { income (cap. } \\
\text { income + cash } \\
\text { transfers) }\end{array}$ & $\begin{array}{l}\text { Capital } \\
\text { income }\end{array}$ & $\begin{array}{c}\text { Cash } \\
\text { trans- } \\
\text { fers }\end{array}$ \\
\hline \multirow{15}{*}{$\begin{array}{l}\text { Single } \\
\text { females and } \\
\text { males }\end{array}$} & \multirow{5}{*}{$\begin{array}{l}\text { Elasticity of the } \\
\text { probability of } \\
\text { participation }\end{array}$} & $\mathrm{I}$ & -0.59 & 0.59 & -0.59 & 0 & 0 & 0 \\
\hline & & II & 0 & 0 & 0 & 0 & 0 & 0 \\
\hline & & III-VII & -0.71 & -0.13 & -0.64 & -0.12 & -0.12 & -0.06 \\
\hline & & IV & -1.38 & -0.34 & -1.38 & -0.33 & 0 & -0.33 \\
\hline & & $\mathrm{X}$ & -1.33 & -1.00 & -1.00 & -0.83 & -0.83 & 0 \\
\hline & \multirow{5}{*}{$\begin{array}{l}\text { Elasticity of the } \\
\text { conditional } \\
\text { expectation of total } \\
\text { supply of hours }\end{array}$} & $\mathrm{I}$ & 0.43 & -0.16 & 0.43 & 0 & 0 & 0 \\
\hline & & II & 0 & 0 & 0 & 0 & 0 & 0 \\
\hline & & III-VII & 0.08 & 0.02 & 0.09 & 0.05 & 0.05 & 0.05 \\
\hline & & IV & -0.21 & -0.04 & -0.21 & 0.05 & 0 & 0.05 \\
\hline & & $\mathrm{X}$ & -0.51 & 0.16 & -0.47 & -0.42 & 0.01 & -0.40 \\
\hline & \multirow{5}{*}{$\begin{array}{l}\text { Elasticity of the } \\
\text { unconditional } \\
\text { expectation of total } \\
\text { supply of hours }\end{array}$} & $\mathrm{I}$ & -0.18 & 0.42 & -0.18 & 0 & 0 & 0 \\
\hline & & II & 0 & 0 & 0 & 0 & 0 & 0 \\
\hline & & III-VII & -0.63 & -0.11 & -0.56 & -0.07 & -0.07 & -0.01 \\
\hline & & IV & -1.56 & -0.22 & -1.42 & -0.29 & 0 & -0.29 \\
\hline & & $\mathrm{X}$ & -1.81 & -0.86 & -1.42 & -1.22 & -0.82 & -0.40 \\
\hline \multirow{15}{*}{$\begin{array}{l}\text { Married/coha } \\
\text { b. females } \\
\text { and males }\end{array}$} & \multirow{5}{*}{$\begin{array}{l}\text { Elasticity of the } \\
\text { probability of } \\
\text { participation }\end{array}$} & I & 0 & 0 & 0 & 0 & 0 & 0 \\
\hline & & II & 0 & 0 & 0 & 0.07 & 0.14 & 0.07 \\
\hline & & III-VII & -0.16 & $-0-06$ & -0.11 & -0.17 & -0.17 & -0.10 \\
\hline & & IV & -0.23 & -0.12 & 0 & -0.46 & -0.29 & -0.17 \\
\hline & & $\mathrm{X}$ & -0.81 & -0.54 & -0.27 & -0.82 & -0.57 & -0.25 \\
\hline & \multirow{5}{*}{$\begin{array}{l}\text { Elasticity of the } \\
\text { conditional } \\
\text { expectation of total } \\
\text { supply of hours }\end{array}$} & I & 0 & 0 & 0 & 0 & 0 & 0 \\
\hline & & II & -0.05 & -0.10 & -0.10 & -0.08 & 0.01 & -0.12 \\
\hline & & III-VII & -0.05 & 0.01 & -0.03 & -0.03 & 0 & -0.03 \\
\hline & & IV & -0.14 & -0.06 & 0 & -0.01 & -0.01 & 0.03 \\
\hline & & $\mathrm{X}$ & -0.22 & -0.22 & 0.10 & -0.32 & -0.13 & -0.13 \\
\hline & \multirow{5}{*}{$\begin{array}{l}\text { Elasticity of the } \\
\text { unconditional } \\
\text { expectation of total } \\
\text { supply of hours }\end{array}$} & I & 0 & 0 & 0 & 0 & 0 & 0 \\
\hline & & II & -0.05 & -010 & -0.10 & -0.01 & 0.16 & -0.04 \\
\hline & & III-VII & -0.21 & -0.05 & -0.13 & -0.20 & -0.07 & -0.13 \\
\hline & & IV & -0.37 & -0.18 & 0 & -0.47 & -0.30 & -0.14 \\
\hline & & X & -1.01 & -0.75 & -0.17 & -1.11 & -0.69 & -0.38 \\
\hline
\end{tabular}


Table 3.4. Aggregate labour supply elasticities with respect to non-labour income for single and married individuals. Norway 1994

\begin{tabular}{|c|c|c|c|c|c|c|c|}
\hline \multirow[b]{2}{*}{$\begin{array}{l}\text { Family } \\
\text { status }\end{array}$} & \multirow[b]{2}{*}{ Type of elasticity } & \multicolumn{3}{|c|}{ Female elasticities } & \multicolumn{3}{|c|}{ Male elasticities } \\
\hline & & $\begin{array}{c}\text { Non-labour } \\
\text { income (cap. } \\
\text { income + cash } \\
\text { transfers) }\end{array}$ & $\begin{array}{l}\text { Capital } \\
\text { income }\end{array}$ & $\begin{array}{l}\text { Cash } \\
\text { trans- } \\
\text { fers }\end{array}$ & $\begin{array}{c}\text { Non-labour } \\
\text { income (cap. } \\
\text { income + cash } \\
\text { transfers) }\end{array}$ & $\begin{array}{l}\text { Capital } \\
\text { income }\end{array}$ & $\begin{array}{c}\text { Cash } \\
\text { trans- } \\
\text { fers }\end{array}$ \\
\hline \multirow{3}{*}{$\begin{array}{l}\text { Single } \\
\text { females } \\
\text { and males }\end{array}$} & $\begin{array}{l}\text { Elasticity of the probability of } \\
\text { participation }\end{array}$ & -0.79 & -0.20 & -0.71 & -0.19 & 0 & -0.08 \\
\hline & $\begin{array}{l}\text { Elasticity of the conditional } \\
\text { expectation of total supply of hours }\end{array}$ & -0.09 & -0.03 & -0.06 & -0.05 & -0.15 & -0.02 \\
\hline & $\begin{array}{l}\text { Elasticity of the unconditional } \\
\text { expectation of total supply of hours }\end{array}$ & -0.89 & -0.23 & -0.77 & -0.23 & -0.16 & -0.09 \\
\hline \multirow{3}{*}{$\begin{array}{l}\text { Married/coh } \\
\text { females and } \\
\text { males }\end{array}$} & $\begin{array}{l}\text { Elasticity of the probability of } \\
\text { participation }\end{array}$ & -0.20 & -0.11 & -0.09 & -0.23 & -0.12 & -0.10 \\
\hline & $\begin{array}{l}\text { Elasticity of the conditional } \\
\text { expectation of total supply of hours }\end{array}$ & -0.09 & -0.04 & -0.02 & -0.10 & -0.04 & -0.05 \\
\hline & $\begin{array}{l}\text { Elasticity of the unconditional } \\
\text { expectation of total supply of hours }\end{array}$ & -0.30 & -0.15 & -0.11 & -0.32 & -0.16 & -0.15 \\
\hline
\end{tabular}

\section{The framework of the social planner}

Since the microeconomic model that is used in this study allows variation in preferences for leisure and comsumption and moreover some individuals live as singles whereas others form families and live together it does not make sense to treat the estimated utility functions as comparable individual welfare functions. Thus, it is required to introduce measures of individual welfare that justify interpersonal comparisons. Section 4.1 explains the method used for dealing with this problem, whereas Section 4.2 discusses the methods that will be used for aggregating individual welfare levels.

\subsection{Specification and estimation of individual welfare functions}

As is universally recognized a social planner needs to compare gains in welfare of some to losses in welfare of others as part of the evaluation of a tax reform. It is non-controversial to assume that each individual's welfare increases with increasing income and leisure as is also captured by the householdspecific utility functions. However, since the preferences as specified in the behavioural model are heterogeneous and moreover we include in the sample both singles and couples, we face the problem of interpersonal comparability when the household utilities are assumed to represent individual welfare levels ${ }^{5}$. To solve the comparability problem the social planner may treat all individuals as

\footnotetext{
${ }^{5}$ See Boadway et al. (2002) and Fleurbaey and Maniquet (2006) for a discussion of interpersonal comparability of utility when preferences for leisure differ between individuals.
} 
singles and introduce an individual welfare function (a common utility function) where we adjust for scale economies in consumption by dividing couples' income by the square root of 2 . Each of the two adult partners is assumed to enjoy the resulting income (y). The formal definition of the individual welfare function $(V)$ determined by the social planner is given by

$$
\log V(y, h)=\gamma_{2}\left(\frac{y^{\gamma_{1}}-1}{\gamma_{1}}\right)+\gamma_{4}\left(\frac{L^{\gamma_{3}}-1}{\gamma_{3}}\right)
$$

where $L$ is leisure, defined as $L=1-(h / 8736)$, and y is the individual's income after tax defined by

$$
y= \begin{cases}c=f(w h, I) & \text { for singles } \\ \frac{c}{\sqrt{2}}=\frac{1}{\sqrt{2}} f\left(w_{F} h_{F}, w_{M} h_{M}, I\right) & \text { for married/cohab. individuals. }\end{cases}
$$

Since the chosen combinations of leisure and disposable income depends on the availability of various job opportunities, we use a similar method for determining the parameters of the individual welfare functions as the one used for determining the parameters of the utility functions for singles and couples. Thus, expression (2.4), where the systematic part of the utility function $(v)$ is replaced by the individual welfare function $(V)$ will form the basis for estimating the parameters of $V$ defined by (4.1). Note, however, that the previously estimated distributions of offered hours and wages will be inserted for $p$ in (2.4). In this context the intuition behind equation (2.4) is that the proportion of the population with disposable income $y$ and leisure $L=1-(h / 8736)$ can be expressed as the welfare value of $(y, L)$, weighted by a measure $p$ of how available this income-leisure combination is. The estimated parameters for the individual welfare functions are reported in Table 4.1.

Table 4.1. Estimates of the parameters of the welfare functions for individuals 20 - 62 years old, Norway 1994

\begin{tabular}{lccr}
\hline Variable & Parameter & Estimate & Stand.de. \\
\hline Income after tax $(\boldsymbol{y})$ & $\gamma_{1}$ & -0.649 & 0.086 \\
& $\gamma_{2}$ & 3.026 & 0.138 \\
Leisure $(\boldsymbol{L})$ & & & \\
& $\gamma_{3}$ & -12.262 & 0.556 \\
& $\gamma_{4}$ & 0.045 & 0.011
\end{tabular}


The results in Table 4.1 demonstrate that the curvature parameters of the income and leisure terms are statistically significant and make these terms increasing concave.

\subsection{Social Welfare Functions}

The informational structure of the individual welfare functions defined by (4.1) allows comparisoin of welfare gains and losses of different individuals due to a policy change. When evaluating the distribution of individual welfare effects of a tax system and/or a tax reform it is required to summarize the gains and losses by a social welfare function. The simplest welfare function is the one that adds up the comparable welfare gains ( $V$ defined by (4.1)) over individuals. The objection to the linear additive welfare function is that the individuals are given equal welfare weights, independent of whether they are poor or rich. Concern for distributive justice requires, however, that poor individuals are assigned larger welfare weights than rich individuals. This structure is captured by the following family of rank-dependent welfare functions ${ }^{6}$,

$$
W_{k}=\int_{0}^{1} p_{k}(t) F^{-1}(t) d t, \quad k=1,2, \ldots,
$$

where $F^{-1}$ is the left inverse of the cumulative distribution function of the individual welfare levels $V$ with mean $\mu$, and $p_{k}(t)$ is a weight function defined by

$$
p_{k}(t)= \begin{cases}-\log t, & k=1 \\ \frac{k}{k-1}\left(1-t^{k-1}\right), & k=2,3, \ldots\end{cases}
$$

Note that the inequality aversion exhibited by $W_{k}$ decreases with increasing $\mathrm{k}$. As $k \rightarrow \infty, W_{k}$ approaches inequality neutrality and coincides with the linear additive welfare function defined by

$$
W_{\infty}=\int_{0}^{1} F^{-1}(t) d t=\mu
$$

It follows by straightforward calculations that $W_{k} \leq \mu$ for all $\mathrm{j}$ and that $W_{k}$ is equal to the mean $\mu$ for finite $k$ if and only if $F$ is the egalitarian distribution. Thus, $W_{k}$ can be interpreted as the equally distributed individual welfare level. As recognized by Yaari (1988) this property suggests that $I_{k}$, defined by

\footnotetext{
${ }^{6}$ This famiy has its origin form Mehran (1976) and Yaari (1988). Several other authors have discussed rationales for rankdependent measures of inequality and social welfare, see e.g. Sen (1974), Hey and Lambert (1980), Donaldson and Weymark (1980, 1983), Weymark (1981), Ben Porath and Gilboa (1992) and Aaberge (2001).
} 


$$
I_{k}=1-\frac{W_{k}}{\mu}, k=1,2, \ldots
$$

can be used as a summary measure of inequality and moreover is a member of the "illfare-ranked single-series Ginis" class introduced by Donaldson and Weymark (1980). As noted by Aaberge (2000), $I_{1}$ is actually equivalent to a measure of inequality that was proposed by Bonferroni (1930), whilst $I_{2}$ is the Gini coefficient. ${ }^{7}$ In this paper we will measure individual welfare level with a common utility function (see Section 4).

To ease the interpretation of the inequality aversion profiles exhibited by $W_{1}, W_{2}, W_{3}$ and $W_{\infty}$ Table 4.2 provides ratios of the corresponding weights - as defined by (4.4) - of the median individual and the 5 per cent poorest, the 30 per cent poorest and the 5 per cent richest individual for different social welfare criteria. As can be observed from the weight profiles provided by Table $4.2 W_{1}$ will be particular sensitive to changes in policies that affect the welfare of the poor.

Table 4.2. Distributional weight profiles of four different social welfare functions

\begin{tabular}{lcccc}
\hline & $\begin{array}{c}W_{1} \\
\text { (Bonferroni) }\end{array}$ & $\begin{array}{c}W_{2} \\
(\text { Gini) }\end{array}$ & $W_{3}$ & $\begin{array}{c}W_{\infty} \\
\text { (Utilitarian) }\end{array}$ \\
\hline $\mathrm{p}(.05) / \mathrm{p}(.5)$ & 4,32 & 1,90 & 1,33 & 1 \\
$\mathrm{p}(.30) / \mathrm{p}(.5)$ & 1,74 & 1,40 & 1,21 & 1 \\
$\mathrm{p}(.95) / \mathrm{p}(.5)$ & 0,07 & 0,10 & 0,13 & 1 \\
\hline
\end{tabular}

For a given total welfare (i.e. the sum of individual welfare levels) the welfare functions $W_{1}$, $W_{2}$, and $W_{3}$ take their maximum value when everyone receives the same income and may thus be interpreted as Equality-of-Outcome criteria (EO) when employed as a measure for evaluating tax systems.

However, as indicated by Roemer (1998) the EO criterion is controversial and suffers from the drawback of receiving little support among citizens in a nation. ${ }^{8}$ This is due to the fact that differences in outcomes resulting from differences in efforts are, by many, considered ethically acceptable and thus should not be the target of a redistribution policy. An egalitarian redistribution policy should instead seek to equalize those differentials in individual welfare arising from factors beyond the control of the individual. Thus, not only the outcome, but its origin and how it was obtained, matters. This is the essential idea behind Roemer's (1998) theory of equality of opportunity,

\footnotetext{
${ }^{7}$ For further discussion of the family $\left\{I_{k}: k=1,2, \ldots\right\}$ of inequality measures we refer to Mehran (1976), Donaldson and Weymark (1980, 1983), Bossert (1990) and Aaberge (2000, 2001).

${ }^{8}$ See also Dworkin (1981a, 1981b), Arneson (1989, 1990), Cohen (1989) and Roemer (1993).
} 
where people are supposed to differ with respect to circumstances, which are attributes of the environment of the individual that influence her earning potential, and which are "beyond her control". This concept is interesting from the policy point-of-view, since the majority of citizens in most industrialized countries, although not unfavourable to redistribution, seem sensitive to the way that a certain outcome has been attained. Redistribution is more likely to receive support if it is designed to correct circumstances that are beyond people's control (i.e. opportunities). On the other hand, if a bad outcome is associated with a lack of effort, redistribution would be much less acceptable ${ }^{9}$.

This study defines circumstances by family background, and classifies the individuals into three types according to father's years of education:

- less than 5 years (Type 1),

- 5-8 years (Type 2), and

- more than 8 years (Type 3).

Assume that $F_{j}^{-1}(t)$ is the welfare level of the individual located at the $t^{\text {th }}$ quantile of the income distribution $\left(F_{j}\right)$ of type $j$. The differences in welfare levels within each type are assumed to be due to different degrees of effort for which the individual is to be held responsible, whereas welfare differences that may be traced back to family background are considered to be beyond the control of the individual. As indicated by Roemer (1998) this suggests that we may measure a person's effort by the quantile of the welfare distribution where he is located. Next, Roemer declares that two individuals in different types have expended the same degree of effort if they have identical positions (rank) in the welfare distribution of their type. Thus, an EOp (Equality of Opportunity) tax policy should aim at designing a tax system such that $\min F_{j}^{-1}(t)$ is maximized for each quantile $t$. However, since this criterion is rather demanding and in most cases will not produce a complete ordering of the tax systems under consideration a weaker ranking criterion is required. To this end Roemer (1998) proposes to employ as the social objective the average of the lowest welfare levels at each quantile,

$$
\tilde{W}_{\infty}=\int_{0}^{1} \min _{j} F_{j}^{-1}(t) d t
$$

Thus, $\tilde{W}_{\infty}$ ignores income differences within types and is solely concerned about differences that arise from differential circumstances. By contrast, the EO criteria defined by (4.3) does not distinguish between the different sources that contribute to welfare inequality. As an alternative to (4.3) and (4.7) we introduce the following extended family of EOp welfare functions,

\footnotetext{
${ }^{9}$ Boadway et al. (2002) provide an alternative contribution that deals with the design of the optimal tax system when the social planner is assumed to give different weights to individuals with different preferences.
} 


$$
\tilde{W}_{k}=\int_{0}^{1} p_{k}(t) \min _{j} F_{j}^{-1}(t) d t, k=1,2, \ldots
$$

where $p_{k}(t)$ is defined by (4.4).

The essential difference between $\tilde{W}_{k}$ and $\tilde{W}_{\infty}$ is that $\tilde{W}_{k}$ gives increasing weight to the welfare of lower quantiles in the type-distributions. In this respect $\tilde{W}_{k}$ captures also an aspect of inequality within types. Thus, as apposed to $\tilde{W}_{\infty}$ the weighted EOp criterion $\tilde{W}_{k}$ might account for the effect of circumstances beyond what is captured by fathers' level of education. As explained above, the concern for within type inequality is greatest for the most disadvantaged type, i.e. for the type that forms the largest segment(s) of $\left\{\min _{j} F_{j}^{-1}(t): t \in[0,1]\right\}$.

Note that $\min _{i} F_{i}^{-1}(t)$ defines the inverse of the following cumulative distribution function $(\tilde{F})$,

$$
\tilde{F}(x)=\operatorname{Pr}\left(\tilde{F}^{-1}(T) \leq x\right)=\operatorname{Pr}\left(\min _{i} F_{i}^{-1}(T) \leq x\right)=1-\prod_{i}\left(1-F_{i}(x)\right),
$$

where $T$ is a random variable with uniform distribution function (defined on [0,1]). Thus, we may decompose the EOp welfare functions $\tilde{W}_{k}$ in the same way as with the EOp welfare functions $W_{k}$. Accordingly, we have that

$$
\tilde{W}_{k}=\tilde{W}_{\infty}\left(1-\tilde{I}_{k}\right), \quad k=1,2, \ldots,
$$

where $\tilde{I}_{k}$, defined by

$$
\tilde{I}_{k}=1-\frac{\tilde{W}_{k}}{\tilde{W}_{\infty}}, \quad k=1,2, \ldots
$$

is a summary measure of inequality for the mixture distribution $\tilde{F}$.

Expression (4.10) shows that the EOp welfare functions $\tilde{W}_{k}$ for $k<\infty$ take into account value judgments about the trade-off between the mean income and the inequality in the distribution of welfare for the most EOp disadvantaged people. Thus, $\tilde{W}_{k}$ may be considered as an inequality within type adjusted version of the pure EOp welfare function that was introduced by Roemer (1998). As explained above, the concern for within type inequality is greatest for the most disadvantaged type, i.e. for the type that forms the largest segment(s) of the mixture distribution $\tilde{F}$. Alternatively, $\tilde{W}_{k}$ for 
$k<\infty$ may be interpreted as an EOp welfare function that, in contrast to $\tilde{W}_{\infty}$, gives increasing weight to individuals who occupy low effort quantiles.

Note that the EOp criterion was originally interpreted as more acceptable—from the point of view of individualistic-conservative societies. Our extended EOp welfare functions can be considered as a mixture of the EO welfare functions and the pure EOp welfare function; they are concerned about inequality between types as well as inequality within the worst-off $\tilde{F}$ distribution defined by (4.9). EOp looks at what happens to the distribution formed by the most disadvantaged segments of the intersecting type-specific distributions (defined by (4.9)). Moreover, the pure version of the criterion only looks at the mean of the worst-off distribution. By contrast, EO takes into account the whole income distribution. For a given sum of incomes, EO will consider equality of welfare (everyone attains the same level of welfare) as the most desirable welfare distribution. The pure EOp will instead consider equality in mean welfare across types as the ultimate goal. Since the extended EOp combines these two criteria, transfers that reduce the differences in the mean welfare between types as well as the welfare differentials between the individuals within the worst-off distribution are considered equalizing by the extended EOp. Thus, in the case of a fixed total welfare also the extended EOp will consider equality of income as the most desirable distribution. However, by transferring money from the most advantaged type to the most disadvantaged type, EOp inequality may be reduced although transfers may be conflicting with the Pigou-Dalton transfer principle. Whether it is more "efficient" to reduce inequality between or within types depends on the specific situation. When labour supply responses to taxation are taken into account the composition of types in the worst-off distribution will change and depend on the chosen welfare function $\left(\tilde{W}_{k}\right)$ as well as on the considered tax rule. Thus, the large heterogeneity in labour supply responses to tax changes that is captured by our model(s) makes it impossible to state anything on EOp- or EO-optimality before the simulation exercises have been completed.

\section{Optimal tax rules}

The purpose of this section is to present an exercise where we locate the optimal tax rules given a fixed total net tax revenue, from the point of view of EO and EOp criteria. To this end we employ the labour supply model and simulation framework explained in Section 2 and in the Appendix to simulate the labour supply behaviour of single females, single males, and couples that are between 20 and 62 years old. To capture the heterogeneity in preferences we have estimated simultaneously three separate utility functions: one for single females, one for single males and one for couples. 
The search for the optimal tax rule is limited to the class of piecewise-linear rules, with four brackets:

$$
y=\left\{\begin{array}{l}
Z \text { if } Z \leq \mathrm{E} \\
Z-\tau_{1}(Z-E) \text { if } \mathrm{E}<\mathrm{Z} \leq \bar{Z}_{1} \\
Z-\tau_{1}\left(\bar{Z}_{1}-E\right)-\tau_{2}\left(Z-\bar{Z}_{1}\right) \text { if } \bar{Z}_{1}<\mathrm{Z} \leq \bar{Z}_{2} \\
Z-\tau_{1}\left(\bar{Z}_{1}-E\right)-\tau_{2}\left(\bar{Z}_{1}-\bar{Z}_{2}\right)-\tau_{3}\left(Z-\bar{Z}_{2}\right) \text { if } \bar{Z}_{2}<\mathrm{Z}
\end{array}\right.
$$

where $y$ is net available income, $Z$ is gross income, $E$ is the exemption level, $\left(\tau_{1}, \tau_{2}, \tau_{3}\right)$ are the marginal tax rates applied to the three brackets of income above the exemption level, $\bar{Z}_{1}$ is the upper limit of the first bracket and $\bar{Z}_{2}$ is the upper limit of the second bracket. Thus, each particular tax rule is characterized by the six parameters: $E, \tau_{1}, \tau_{2}, \tau_{3}, \bar{Z}_{1}$ and $\bar{Z}_{2}$.

The tax rule specified by (5.1) replaces the current rule as of 1994, which is described by the example of Table 5.1 and also belongs to the class of piece-wise linear tax rules. In this paper we focus on the profile of the marginal tax rates. Therefore we keep unchanged under the alternative tax rules all the current - as of 1994 - welfare policies (social assistance, income support related to disability etc. .). ${ }^{10}$

Table 5.1. Current tax rule in Norway as of 1994 for singles without children and couples without children and with two wage earners

\begin{tabular}{lc}
\hline Gross income (NOK 1994) & Tax \\
\hline$(0-17000)$ & 0 \\
$(17000-24709)$ & $0.25 \mathrm{Y}-4250$ \\
$(24709-28250)$ & $0.078 \mathrm{Y}$ \\
$(28250-140500)$ & $0.302 \mathrm{Y}-6328$ \\
$(140500-208000)$ & $0.358 \mathrm{Y}-14196$ \\
$(208000-234500)$ & $0.453 \mathrm{Y}-33956$ \\
$(234500-)$ & $0.495 \mathrm{Y}-43804$ \\
\hline
\end{tabular}

The identification of the optimal tax rules consists of five steps:

\footnotetext{
${ }^{10}$ In previous exercise - not reported here - we also simulated tax rules that included a positive transfer (on top of current welfare transfers) and it turned out that the optimal transfer was zero or very low, depending on the social welfare criterion.
} 
1. The tax rule is applied to individual earners' gross incomes in order to obtain disposable incomes (income after tax) corresponding to each alternative in the choice set ${ }^{11}$. New labour supply responses in view of a new tax rule are simulated by the household labour supply model.

2. To each decision maker (wife or husband) between 20 and 62 years old, an equivalent income $(y)$ is imputed, computed as total disposable household income $(c)$ divided by the square root of the number of household members. The purpose of this procedure is to convert the distribution of incomes $(c)$ across heterogeneous families into a distribution of (equivalent) incomes $(y)$ across adult individuals.

3. As a result of the previous steps, we now have for each individual a simulated pair $(y, h)$. We then compute the individual welfare levels by applying to the chosen $(y, h)$ the individual welfare (common utility) function (see Section 4).

4. We then compute $W_{k}$ and $\tilde{W}_{k}$ for $k=1,2,3$ and $\infty$.

5. Optimization is performed by iterating the steps $1-4$ in order to find the tax rule from the class (6.1) that produces the highest value of $W_{k}$ or $\tilde{W}_{k}$ for each value of $\mathrm{k}$, under the constraint of constant total tax revenue. In fact we perform two optimization exercises. In the first one, all the tax parameters are unconstrained. This always results in $\tau_{3}=1^{12}$. Since in practice a 100 per cent maximum marginal tax rate could hardly be implemented, we perform a second exercise where $\tau_{3}$ is constrained to be not grater than 0.60 .

The results are reported in Tables 5.2 - 5.7 and in Figures 5.1(a), 5.1(b), 5.2(a) and 5.2(b).

\footnotetext{
${ }^{11}$ We also account for the fact that couples with one wage earner face milder taxation in the sense that all tax brackets above the second bracket in Table 6.1 are widened.

${ }^{12}$ Notice that in our model it is possible that an individual optimizes in the range of income values where the $100 \%$ marginal tax rate is applied, since utility does not only depend on income and hours of work but also on other unobserved job characteristics captured by the stochastic component $\varepsilon$.
} 
Table 5.2 Optimal tax rules according to alternative social welfare criteria ${ }^{(*)}$

\begin{tabular}{c|cccc|cccc}
\hline & \multicolumn{3}{|c|}{ EO-social welfare } & \multicolumn{5}{c}{ EOp-social welfare } \\
\cline { 2 - 9 } & $\begin{array}{c}W_{1} \\
\text { (Bonferroni) }\end{array}$ & $\begin{array}{c}W_{2} \\
\text { (Gini) }\end{array}$ & $W_{3}$ & $\begin{array}{c}W_{\infty} \\
\text { (Utilitarian) }\end{array}$ & $\begin{array}{c}\tilde{W}_{1} \\
\text { (Bonferroni) }\end{array}$ & $\begin{array}{c}\tilde{W}_{2} \\
(\mathrm{Gini})\end{array}$ & $\tilde{W}_{3}$ & $\tilde{W}_{\infty}$ \\
\hline$\tau_{1}$ & 0.16 & 0.22 & 0.22 & 0.22 & 0.14 & 0.17 & 0.17 & 0.20 \\
$\tau_{2}$ & 0.37 & 0.37 & 0.36 & 0.33 & 0.39 & 0.36 & 0.35 & 0.33 \\
$\tau_{3}$ & 1.00 & 1.00 & 1.00 & 1.00 & 1.00 & 1.00 & 1.00 & 1.00 \\
$E$ & 1.00 & 22.00 & 18.00 & 11.00 & 0.00 & 0.00 & 0.00 & 0.00 \\
$\bar{Z}_{1}$ & 161.80 & 217.85 & 234.88 & 272.10 & 148.53 & 173.61 & 169.42 & 237.72 \\
$\bar{Z}_{2}$ & 730.00 & 720.00 & 720.00 & 780.00 & 730.00 & 720.00 & 710.00 & 730.00 \\
\hline
\end{tabular}

(*) E, $\bar{Z}_{1}$ and $\bar{Z}_{2}$ are measured in thousands of 1994 NOK 
Table 5.3 Optimal tax rules according to alternative social welfare criteria ${ }^{(*)} \cdot\left(\tau_{3}\right.$ constrained to be $\leq 0.6$ )

\begin{tabular}{c|cccc|cccc}
\hline & \multicolumn{4}{|c|}{ EO-social welfare } & \multicolumn{4}{c}{ EOp-social welfare } \\
\cline { 2 - 8 } & $\begin{array}{c}W_{1} \\
\text { (Bonferroni) }\end{array}$ & $\begin{array}{c}W_{2} \\
(\mathrm{Gini})\end{array}$ & $W_{3}$ & $\begin{array}{c}W_{\infty} \\
\text { (Utilitarian) }\end{array}$ & $\begin{array}{c}\tilde{W}_{1} \\
\text { (Bonferroni) }\end{array}$ & $\begin{array}{c}\tilde{W}_{2} \\
(\text { Gini) }\end{array}$ & $\tilde{W}_{3}$ & $\begin{array}{c}\tilde{W}_{\infty} \\
\text { (Utilitarian) }\end{array}$ \\
\hline$\tau_{1}$ & 0.17 & 0.20 & 0.23 & 0.22 & 0.15 & 0.17 & 0.20 & 0.21 \\
$\tau_{2}$ & 0.38 & 0.37 & 0.37 & 0.33 & 0.39 & 0.36 & 0.37 & 0.34 \\
$\tau_{3}$ & 0.60 & 0.60 & 0.60 & 0.60 & 0.60 & 0.60 & 0.60 & 0.60 \\
$E$ & 0.00 & 6.00 & 20.00 & 8.00 & 0.00 & 0.00 & 2.00 & 2.00 \\
$\bar{Z}_{1}$ & 172.00 & 210.97 & 243.98 & 263.70 & 151.81 & 164.52 & 226.62 & 255.87 \\
$\bar{Z}_{2}$ & 700.00 & 690.00 & 690.00 & 720.00 & 710.00 & 680.00 & 680.00 & 670.00 \\
\hline
\end{tabular}

(*) E, $\bar{Z}_{1}$ and $\bar{Z}_{2}$ are measured in thousands of 1994 NOK

Tables 5.2 and 5.3 display the optimal tax systems from the unconstrained and the constrained optimization exercise. To ease the comparability of the 1994 tax system and the various optimal tax systems we report average taxes for a selection of gross incomes in Table 5.4. Tables 5.5 and 5.6 illustrate some of the behavioural implications of the optimal tax rules. Table 5.7 displays the percentages of winners under the optimal rule by income deciles of the 1994 income distribution. Figures 5.1(a), 5.1(b), 5.2(a) and 5.2(b) are limited to the EO-optimal tax rules since the EOp-optimal ones are very similar.

a) The tables and the graphs show that the more egalitarian the criterion is, the more progressive is the optimal tax rule. For example the optimal rule according to Bonferroni is more progressive than the optimal rule according to Gini, which in turn is more progressive than the optimal utilitarian rule.

b) The differences implied by using the EO or the corresponding EOp criteria seem negligible. This is interesting since EOp is usually interpreted as a less interventionist criterion than EO. Still, when empirically implemented they both seem to require very similar tax rules, even slightly more progressive the one implied by EOp.

c) Overall, the structure of the optimal rules is not dramatically different from the current rule; all the rules envisage a smooth sequence of increasing marginal tax rates. The optimal rules would imply a 100\% marginal tax rate on very high incomes, but the proportion of households falling in the corresponding income bracket is very low; around 1.7 percent for married/cohab. 
males, 0.5 percent for married/cohabiting females, 1.4 percent for single males and 0 for single females.

d) There are however also two important differences between the current and the optimal rules. First, all the optimal rules imply a higher income after tax for most levels of gross income. In other words, the optimal rules are able to extract the same total tax revenue from a larger total gross income (i.e. applying a lower average tax rate). The result is due to a sufficiently high labour supply response estimated and accounted for by the model. Second, the optimal marginal tax rates applied to average or low-average income brackets are markedly lower than the ones implied by the current tax rule. This result provides a controversial perspective in view of the tax reforms implemented in many developed countries during the last decades. In most cases those reforms embodied the idea of improving efficiency and labour supply incentives through a lower average tax rate and lower marginal tax rates on higher incomes. ${ }^{13}$ Our optimal tax computations give support to the first part (lowering the average tax rate), much less to the second; on the contrary our results suggest that a lower average tax rate should be obtained by lowering the marginal tax rates particularly on low and average income brackets ${ }^{14}$.

e) The differences between the current and the optimal tax rules have important behavioural implications. All the optimal rules imply a larger labour supply and disposable income (income after tax) (Table 5.5). ${ }^{15}$ Since we keep unchanged the total tax revenue also the gross income is larger under the optimal rules. This is due to the fact that the optimal rules induce (some of) the households to move to alternatives with longer hours and/or higher wages.

Table 5.6 shows that the strongest labour supply response comes from households in the lower income deciles, who are those who show a more elastic labour supply (Section 3). Table 5.7 shows the percentage of winners under the optimal rules, by marital status, gender and household income decile under the current 1994 rule, where an individual is defined as a winner if her/his welfare is higher under the new tax rule than under the current 1994 rule. All the optimal rules would "win the referendum" against the current rule, since they all imply a strong majority of winners. The percentage of winners, however, varies substantially across the different demographic subgroups.

\footnotetext{
${ }^{13}$ For example Blundell (1996) reports that during the 80's and early 90's in some countries the top marginal tax rates were cut from 70-80\% down to about 40-50\%. On these issues the discussion in Røed and Strøm (2001) is especially relevant.

${ }^{14}$ A second important difference between our exercise and the implemented reforms referred to in the main text, is that those reforms typically envisaged a reduction of the total tax revenue together with the reduction in the average tax rate, while in our simulations we keep the total tax revenue unchanged.

${ }^{15}$ The (simulated) 1994 levels of participation, hours of work and income are reported in the Appendix.
} 
Table 5.4. Average taxes under the 1994 tax system and various optimal tax systems when the upper marginal tax rate is constrained to be $\leq 60$ percent ${ }^{*}$. Percent

\begin{tabular}{|c|c|c|c|c|c|}
\hline $\begin{array}{l}\text { Gross income } \\
\text { (NOK) }\end{array}$ & 1994 tax system & $\begin{array}{c}\text { The optimal } \\
\text { system under } \\
W_{l}\end{array}$ & $\begin{array}{c}\text { The optimal } \\
\text { system under } \\
W_{\infty}\end{array}$ & $\begin{array}{c}\text { The optimal } \\
\text { system under } \\
\tilde{W}_{1}\end{array}$ & $\begin{array}{c}\text { The optimal } \\
\text { system under } \\
\tilde{W}_{\infty}\end{array}$ \\
\hline 50000 & 17.5 & 17.0 & 18.5 & 15.0 & 20.2 \\
\hline 100000 & 23.9 & 17.0 & 20.2 & 15.0 & 20.6 \\
\hline 150000 & 26.3 & 17.0 & 20.8 & 15.0 & 20.7 \\
\hline 200000 & 28.7 & 19.9 & 21.1 & 20.8 & 20.8 \\
\hline 300000 & 34.9 & 26.0 & 22.7 & 26.9 & 22.8 \\
\hline 400000 & 38.5 & 29.0 & 25.3 & 29.9 & 25.6 \\
\hline 500000 & 40.7 & 30.8 & 26.8 & 31.7 & 27.3 \\
\hline 700000 & 43.2 & 32.8 & 28.6 & 33.8 & 29.9 \\
\hline 1000000 & 45.1 & 41.0 & 37.5 & 41.4 & 39.2 \\
\hline
\end{tabular}

* The tax reates concern singles without children and married/cohabiting persons living in families with two wage earners.

Table 5.5 Percentage changes in participation rates, annual hours of work and disposable income under the EO-optimal tax rules $\left(\tau_{3}\right.$ constrained to be $\leq \mathbf{0 . 6}$ )

\begin{tabular}{|c|c|c|c|c|c|c|c|c|c|}
\hline & \multicolumn{5}{|c|}{ EO-social welfare } & \multicolumn{4}{|c|}{ EOp-social welfare } \\
\hline & & $\begin{array}{c}\mathrm{W}_{1} \\
\text { (Bonferroni) }\end{array}$ & $\begin{array}{c}\mathrm{W}_{2} \\
\text { (Gini) }\end{array}$ & $\mathrm{W}_{3}$ & $\mid \begin{array}{c}\mathrm{W}_{\infty} \\
\text { (Utilitarian) }\end{array}$ & $\mid \begin{array}{c}\tilde{W}_{1} \\
\text { (Bonferroni) }\end{array}$ & $\begin{array}{c}\tilde{W}_{2} \\
\text { (Gini) }\end{array}$ & $\tilde{W}_{3}$ & $\begin{array}{c}\tilde{W}_{\infty} \\
\text { (Utilitarian) }\end{array}$ \\
\hline \multirow{3}{*}{$\begin{array}{l}\text { Single } \\
\text { males }\end{array}$} & Participation rates & 4.5 & 4.9 & 4.5 & 4.9 & 3.4 & 4.5 & 4.9 & 4.9 \\
\hline & Annual hours & 7.0 & 7.5 & 7.4 & 8.9 & 5.4 & 7.0 & 8.2 & 8.7 \\
\hline & Disposable income & 11.2 & 11.8 & 11.8 & 14.7 & 9.5 & 11.2 & 12.5 & 14.1 \\
\hline \multirow{3}{*}{$\begin{array}{l}\text { Sigle } \\
\text { females }\end{array}$} & Participation rates & 4.7 & 6.7 & 6.3 & 7.5 & 3.9 & 4.7 & 7.1 & 7.5 \\
\hline & Annual hours & 6.1 & 9.7 & 9.3 & 12.1 & 4.3 & 6.1 & 11.0 & 12.2 \\
\hline & Disposable income & 4.3 & 6.6 & 6.3 & 8.7 & 3.0 & 4.3 & 7.6 & 8.9 \\
\hline \multirow{5}{*}{ Couples } & Participation rates, $\mathrm{M}$ & 2.2 & 2.7 & 2.8 & 3.5 & 1.9 & 2.5 & 2.9 & 3.4 \\
\hline & Participation rates, F & 2.7 & 2.4 & 1.9 & 1.4 & 2.7 & 2.6 & 2.5 & 1.9 \\
\hline & Annual hours, $\mathrm{M}$ & 6.4 & 7.8 & 8.4 & 11.6 & 5.1 & 7.2 & 8.8 & 11.1 \\
\hline & Annual hours, $\mathrm{F}$ & 6.2 & 7.0 & 5.4 & 5.5 & 5.5 & 5.7 & 7.1 & 6.2 \\
\hline & Disposable income & 8.7 & 10.7 & 11.0 & 14.6 & 7.1 & 9.7 & 11.5 & 14.2 \\
\hline
\end{tabular}


Table 5.6 Percentage changes in labour supply (total hours) by household income decile under the EO-optimal tax rules $\left(\tau_{3}\right.$ constrained to be $\left.\leq \mathbf{0 . 6}\right)$

\begin{tabular}{|c|c|c|c|c|c|c|c|c|c|}
\hline & & \multicolumn{2}{|c|}{$\begin{array}{c}\mathrm{W}_{1} \\
\text { (Bonferroni) }\end{array}$} & \multicolumn{2}{|c|}{$\begin{array}{c}\mathrm{W}_{2} \\
\text { (Gini) }\end{array}$} & \multicolumn{2}{|c|}{$\mathrm{W}_{3}$} & \multicolumn{2}{|c|}{$\frac{\mathrm{W}_{\infty}}{\text { (Utilitarian) }}$} \\
\hline & \multirow{2}{*}{$\begin{array}{l}\text { Household } \\
\text { income } \\
\text { decile }\end{array}$} & & & & & & & & \\
\hline & & Male & Female & Male & Female & Male & Female & Male & Female \\
\hline \multirow{6}{*}{ Singles } & I & 89.5 & 65.9 & 97.9 & 83.6 & 95.7 & 62.2 & 108.4 & 97.8 \\
\hline & II & 17.9 & 25.2 & 22.7 & 36.8 & 19.6 & 36,8 & 26.2 & 44.1 \\
\hline & III-VIII & 2.8 & 3.0 & 2.8 & 6.5 & 3.1 & 7.4 & 3.2 & 8.9 \\
\hline & IX & 0.0 & 0.0 & 0.0 & 0.0 & 0.0 & 0.0 & 2.5 & -0.4 \\
\hline & $\mathrm{X}$ & 1.2 & 0.0 & 0.0 & 0.0 & 0.0 & 0.0 & 1.2 & 0.0 \\
\hline & All & 7.0 & 6.1 & 7.5 & 9.7 & 7.4 & 9.3 & 8.9 & 12.1 \\
\hline \multirow{6}{*}{ Couples } & I & 36.3 & 47.8 & 43.8 & 54.1 & 42.0 & 55.7 & 54.3 & 61.7 \\
\hline & II & 22.9 & 13.4 & 29.1 & 17.4 & 32.0 & 12.5 & 42.3 & 16.3 \\
\hline & III-VIII & 4.2 & 4.6 & 5.0 & 4.7 & 5.9 & 2.7 & 8.6 & 1.9 \\
\hline & IX & 1.5 & -0.2 & 1.7 & 0.0 & 1.3 & 0.4 & 1.7 & 0.0 \\
\hline & $\mathrm{X}$ & -0.7 & -1.5 & -0.8 & -0.8 & -0.8 & -1.5 & -0.3 & -0.8 \\
\hline & All & 6.4 & 6.2 & 7.8 & 7.0 & 8.4 & 5.4 & 11.6 & 5.5 \\
\hline
\end{tabular}


Table 5.7. Percentage of winners under the EO-optimal tax rules $\left(\tau_{3}\right.$ constrained to be $\left.\leq \mathbf{0 . 6}\right)$

\begin{tabular}{|c|c|c|c|c|c|c|c|c|c|}
\hline & & \multicolumn{2}{|c|}{$\begin{array}{l}\mathrm{W}_{1} \\
\text { (Bonferroni) }\end{array}$} & \multicolumn{2}{|l|}{$\begin{array}{l}\mathrm{W}_{2} \\
\text { (Gini) }\end{array}$} & \multicolumn{2}{|l|}{$\mathrm{W}_{3}$} & \multicolumn{2}{|c|}{$\begin{array}{l}\mathrm{W}_{\infty} \\
\text { (Utilitarian) }\end{array}$} \\
\hline & \multirow{2}{*}{$\begin{array}{l}\text { Household } \\
\text { income } \\
\text { decile }\end{array}$} & & & & & & & & \\
\hline & & Male & Female & Male & Female & Male & Female & Male & Female \\
\hline \multirow{6}{*}{ Singles } & I & 0.74 & 0.74 & 0.74 & 0.74 & 0.74 & 0.71 & 0.61 & 0.74 \\
\hline & II & 0.68 & 0.55 & 0.61 & 0.55 & 0.61 & 0.55 & 0.52 & 0.48 \\
\hline & III-VIII & 0.83 & 0.69 & 0.81 & 0.68 & 0.78 & 0.68 & 0.72 & 0.65 \\
\hline & IX & 0.77 & 0.42 & 0.84 & 0.48 & 0.84 & 0.48 & 0.84 & 0.55 \\
\hline & $\mathbf{X}$ & 0.77 & 0.39 & 0.87 & 0.42 & 0.90 & 0.45 & 0.87 & 0.52 \\
\hline & All & 0.79 & 0.62 & 0.79 & 0.63 & 0.78 & 0.62 & 0.71 & 0.62 \\
\hline \multirow{6}{*}{ Couples } & I & 0.62 & 0.63 & 0.62 & 0.63 & 0.61 & 0.63 & 0.59 & 0.62 \\
\hline & II & 0.70 & 0.70 & 0.70 & 0.70 & 0.68 & 0.69 & 0.68 & 0.71 \\
\hline & III-VIII & 0.79 & 0.82 & 0.80 & 0.83 & 0.79 & 0.83 & 0.78 & 0.84 \\
\hline & IX & 0.80 & 0.83 & 0.83 & 0.86 & 0.84 & 0.86 & 0.88 & 0.90 \\
\hline & $\mathbf{X}$ & 0.74 & 0.74 & 0.75 & 0.75 & 0.75 & 0.75 & 0.78 & 0.79 \\
\hline & All & 0.76 & 0.78 & 0.77 & 0.79 & 0.76 & 0.79 & 0.76 & 0.81 \\
\hline
\end{tabular}


Figure 5.1(a)

GUบSS Man OAt 16 16:25:33 2008

EO-Optimal tax rules vs current rule

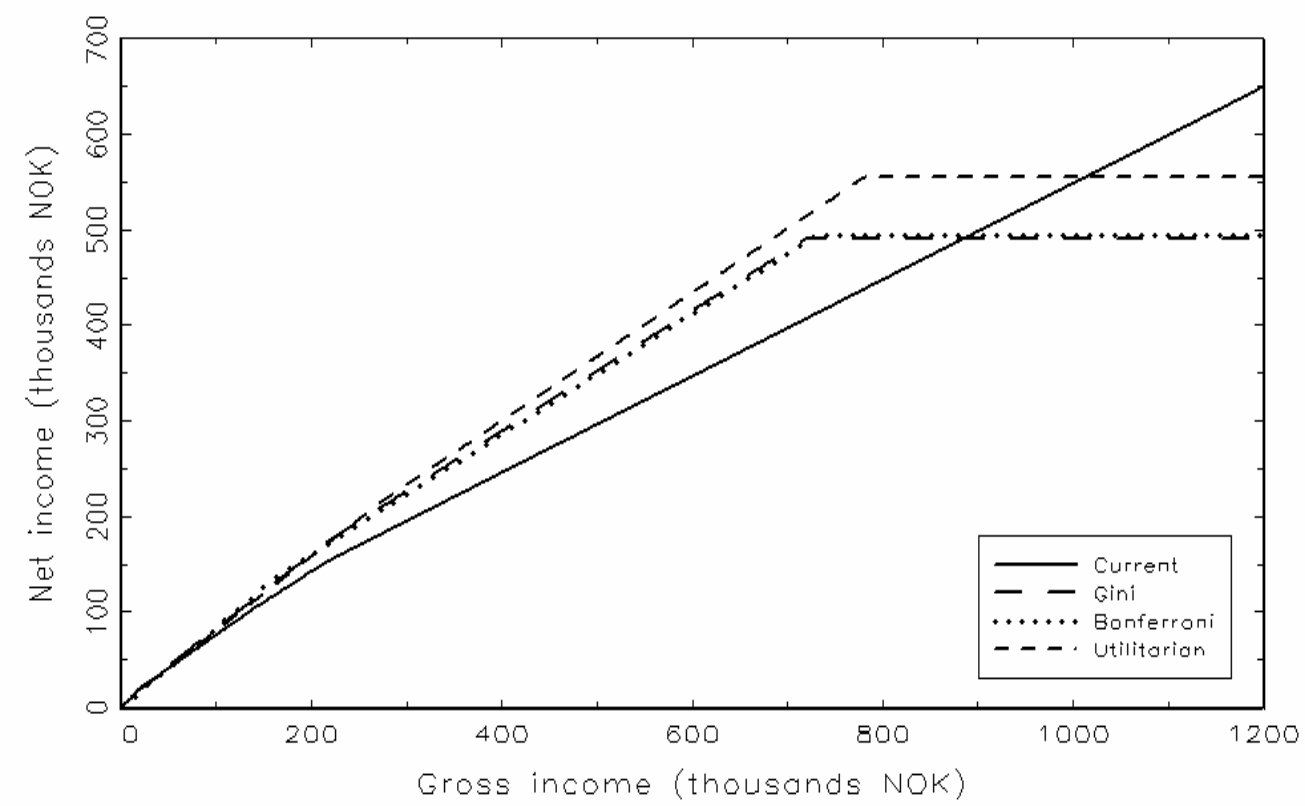

Figure 5.1(b). Zoom on low incomes

GüSS Man OC1 18 16:28:42 2008

EO-Optimal tax rules vs current rule

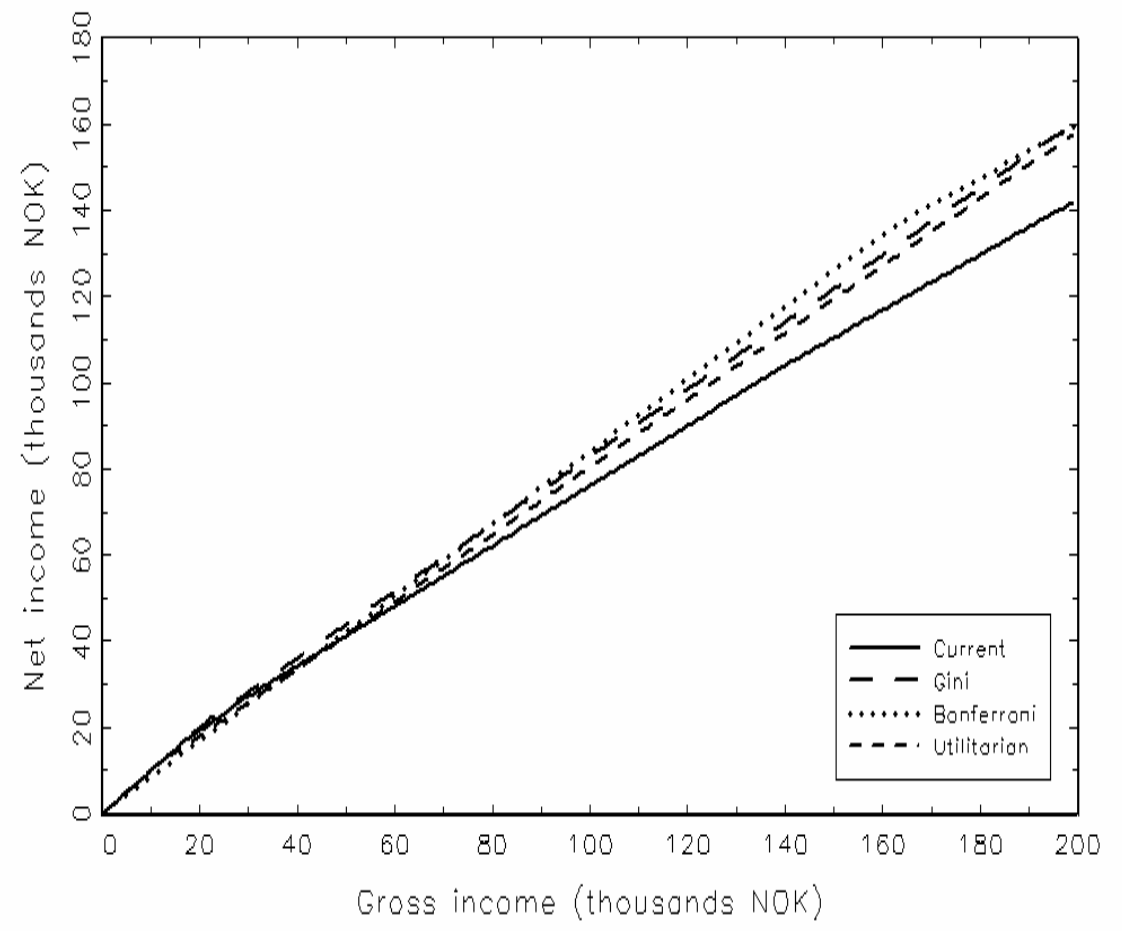


Figure 5.2(a)

gaUSS Man OAT 18 18:30:56 2008

EO-Optimal tax rules vs current rule - Max marginal rate $=60 \%$

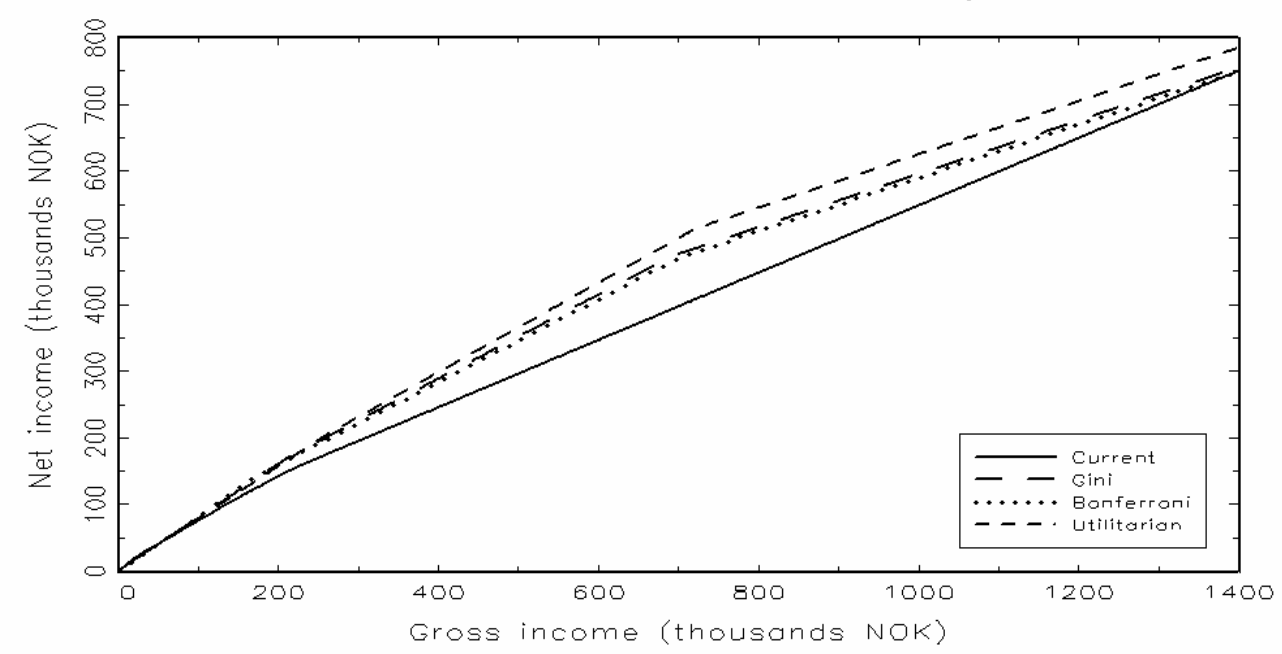

Figure 5.2(b). Zoom on low incomes

GuUS Man ON 18 18:31:18 2008

EO-Optimal tax rules vs current rule - Max marginal rate $=60 \%$

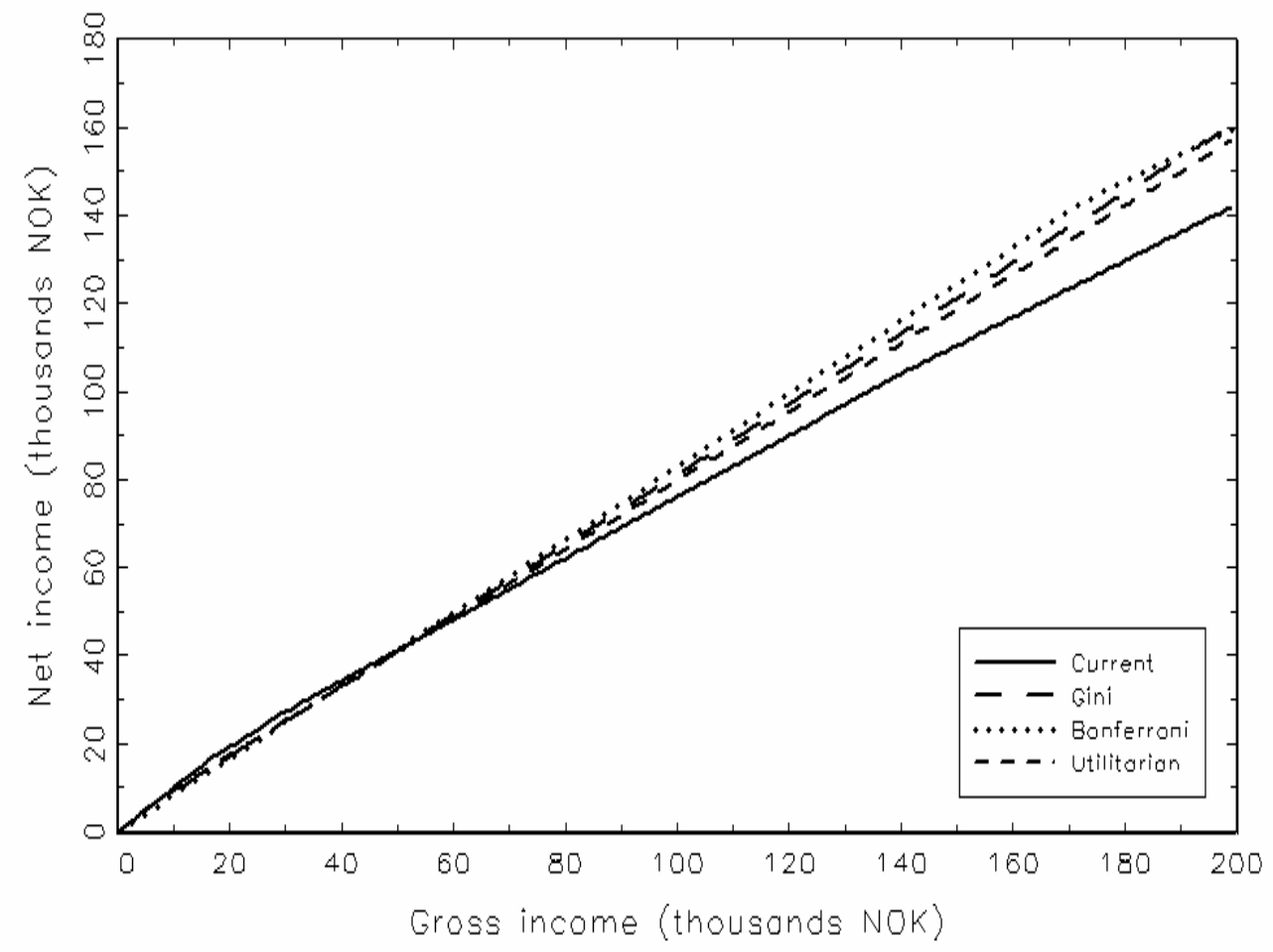




\section{Conclusions}

We have performed an exercise in designing optimal income taxes that - differently from what is typically done in the literature - does not rely on a priori theoretical optimal taxation results, but instead use a microeconometric model of labour supply in order to directly maximize a social welfare function with respect to a parametrically defined income tax rule. The microeconometric model can be considered as an extension of the standard multinomial logit model, and is designed to allow for a detailed description of complex choice sets and budget constraints. This model differs from the traditional marginal criteria models of labor supply in several respects. First, it accounts for observed as well as unobserved heterogeneity in tastes and allows for constraints in the choice of hours of work. Second, it includes both single person households and married/cohabiting couples and allows for simultaneous treatment of both spouses choices. Third, the model allows for an exact representation of income taxes. The model, which contains 78 parameters that capture the heterogeneity in preferences as well as in opportunities among households and individuals, is estimated on the basis of Norwegian micro data from 1995. The estimated model is for a given tax rule used to simulate the choices made by single individuals and couples. Those choices are therefore generated by preferences and opportunities that vary across the decision units. We identify optimal tax rules - within a class of 6parameter piece-wise linear rules - by iteratively running the model until the social welfare function is maximized under the constraint of keeping constant the total net tax revenue.

We focus on the profile of the marginal tax rates and keep fixed the current (1994) system of transfers, income support and social assistance policies. We explore a variety of different social welfare criteria. More egalitarian social welfare function tends to imply more progressive tax rules. The two alternative social welfare criteria, EO and EOp do not seem to entail major differences in the corresponding optimal tax rules. A first striking result is that, irrespective of the social welfare criterion used, the top optimal marginal tax rate always turns out to be 100 per cent for sufficiently high gross income levels (approximately above 700000 Norwegian Kroner (1994) $\approx 87000$ Euros). Second, all the optimal tax rules imply an average tax rate lower than the current 1994 one. Third, all the optimal rules imply - with respect to the current rule - lower marginal rates on low and/or average income levels and higher marginal rates on sufficiently high income levels. The pattern of labour supply elasticities illustrated in Section 3 contributes to explaining the profile of the optimal tax rules. Our results are partially at odds with the tax reforms that took place in many countries during the last decades. While those reforms embodied the idea of lowering average tax rates, the way to implement it has typically consisted in reducing the top marginal rates. Our results instead suggest lower average tax rates by reducing marginal rates on low and average income levels and increasing marginal rates on very high income levels. 


\section{References}

Aaberge, R. (2000): Characterizations of Lorenz Curves and Income Distributions, Social Choice and Welfare, 17, 639-653.

Aaberge, R. (2001): Axiomatic Characterization of the Gini Coefficient and Lorenz Curve Orderings, Journal of Economic Theory, 101, 115-132.

Aaberge, R., Colombino, U. and S. Strøm (1999): Labour Supply in Italy: An Empirical Analysis of Joint Household Decisions, with Taxes and Quantity Constraints, Journal of Applied Econometrics, $14,403-422$.

Aaberge, R., Colombino, U. and S. Strøm (2000): Labour Supply Responses and Welfare Effects from Replacing Current Tax Rules by a Flat Tax: Empirical Evidence from Italy, Norway and Sweden, Journal of Population Economics, 13, 595-621.

Aaberge, R., Colombino, U. and S. Strøm (2004): Do More Equal Slices Shrink the Cake? An Empirical Investigation of Tax-Transfer Reform Proposals in Italy, Journal of Population Economics, $17,767-785$.

Aaberge R., U. Colombino, S. Strøm and T. Wennemo (2000): Joint Labour Supply of Married Couples: Efficiency and Distribution Effects of Tax and Labour Market Reforms. In: Mitton L., Sutherland H. and M. Weeks (eds.) Micro-simulation Modelling for Policy Analysis: Challenges and Innovations, Cambridge University Press.

Aaberge, R., J.K. Dagsvik and S. Strøm (1995): Labour Supply Responses and Welfare Effects of Tax Refoms, Scandinavian Journal of Economics, 97, 635-659.

Arneson, R. (1989): Equality and Equality of Opportunity for Welfare, Philosophical Studies, 56, 7793.

Arneson, R. (1990): Liberalism, Distributive Subjectivism, and Equal Opportunity for Welfare, Philosophy \& Public Affairs, 19, 159-194.

Ben-Akiva, M. and T. Watanatada (1981): “Application of a Continuous Spacial Choice Logit Model", in Manski, C. F. and McFadden D. (eds.) Structural Analysis of Discrete Data with Econometric Applications, MIT Press.

Ben Porath, E. and I. Gilboa (1994): Linear Measures, the Gini Index, and the Income-Equality Tradeoff, Journal of Economic Theory, 64, 443-467.

Blundell, R. (1996): Labour Supply and Taxation. In Devereux, M. (ed.): The Economics of Tax Policy, Oxford University Press.

Blundell, R., Brewer, M., Haan P. and A. Shephard (2006): Optimal Income Taxation of Lone Mothers: an Empirical Comparison for Germany and the UK, mimeo.

Boadway R., Marchand M., Pestieau P. and M. Racionero (2002): Optimal Redistribution with Heterogeneous Preferences for Leisure, Journal of Public Economic Theory, 4, 475 - 498.

Bonferroni, C. (1930): Elementi di Statistica Generale. Seeber, Firenze. 
Bossert, W. (1990): An Approximation of the Single-series Ginis, Journal of Economic Theory, 50, 82-92.

Bourguignon, F. and A. Spadaro (2005): Tax-Benefit Revealed Social Preferences, PSE Working Papers, 2005-22.

Bourguignon, F. and A. Spadaro (2006): Microsimulation as a Tool for Evaluating Redistribution Policies, Journal of Economic Inequality, 4, 77 - 106.

Cohen, G.A. (1989): On the Currency of Egalitarian Justice, Ethics, 99, 906-944.

Dagsvik, J.K. (1994): Discrete and Continuous Choice, Max-Stable Processes and Independence from Irrelevant Attributes, Econometrica, 62, 1179-1205.

Diamond, P. (1980): Income Taxation with Fixed Hours of Work, Journal of Public

Economics, 12, 101-110.

Dickens, W. and S. Lundberg (1993): Hours Restrictions and Labour Supply, International Econonomic Review, 34, 169-191.

Donaldson, D. and J.A. Weymark (1980): A Single Parameter Generalization of the Gini Indices of Inequality, Journal of Economic Theory, 22, 67-86.

Donaldson, D. and J.A. Weymark (1983): Ethically flexible Indices for Income Distributions in the Continuum, Journal of Economic Theory, 29, 353-358.

Dworkin, R. (1981a): What is Equality? Part 1: Equality of Welfare, Philosophy \& Public Affairs, 10, 185-246.

Dworkin, R. (1981b): What is Equality? Part 2: Equality of Resources, Philosophy \& Public Affairs, 10, 283-345.

Euwals, R. and A. van Soest (1999), Desired and actual labor supply of unmarried men and women in the Netherlands, Labor Economics, 6, 95-118.

Fleurbaey, M. and F. Maniquet (2006): Fair Income Tax, Review of Economic Studies, 73, 55-84.

Fortin, B., Truchon, M. and L. Beauséjour (1993): "On Reforming the Welfare System: Workfare meets the Negative Income Tax", Journal of Public Economics, 31, 119-151.

Hey, J. D. and P. J. Lambert (1980): Relative Deprivation and the Gini Coefficient: Comment, Quarterly Journal of Economics, 94, 567-573.

Laroque, G. (2005): Income Maintenance and Labour Force Participation, Econometrica, 73, 341376

Mehran, F. (1976): Linear Measures of Inequality, Econometrica, 44, 805-809.

Mirlees, J. A. (1971): An Exploration in the Theory of Optimal Income Taxation: Review of Economic Studies, 38, 175-208. 
Roemer, J. (1993): A Pragmatic Theory of Responsibility for the Egalitarian Planner, Philosophy \& Public Affairs, 10, 146-166.

Roemer, J. (1998): Equality of Opportunity, Harvard University Press.

Roemer, J. E., Aaberge, R., Colombino, U., Fritzell, J., Jenkins, S. P., Lefranc, A., Marx, I., Page, M., Pommer, E. and J. Ruiz-Castillo (2003): To what Extent Do Fiscal Regimes Equalize Opportunities for Income Acquisition among Citizens?, Journal of Public Economics, 87, 539-565.

Røed, K. and S. Strøm (2002): Progressive Taxes and the Labour Market - Is the Trade-Off between Equality and Efficiency Inevitable?, Journal of Economic Surveys, 16, 77-100.

Saez, E. (2001): Using Elasticities to Derive Optimal Income Tax Rates, Review of Economic Studies, $68,205-229$.

Saez, E. (2002): Optimal Income Transfer Programs: Intensive versus Extensive Labour Supply Responses, Quarterly Journal of Economics, 117, 1039-1073.

Sen, A. (1974): Informational Bases of alternative Welfare Approaches, Journal of Public Economics, 3, 387-403.

Tuomala, M. (1990): Optimal Income Tax and Redistribution, Clarendon Press, Oxford.

Weymark, J. (1981): Generalised Gini Inequality Indices, Mathematical Social Sciences, 1, 409-430.

Yaari, M.E. (1988): A controversial Proposal Concerning Inequality Measurement, Journal of Economic Theory, 44, 381-397. 


\section{Appendix}

\section{The microeconometric model - Empirical specification and estimation results}

The modelling approach of this paper differs from the traditional textbook model by treating the utility function as a random variable and analyzing labour supply as a random utility maximization problem. This framework can be considered as an extension of the standard multinomial logit model; see Dagsvik (1994) and Aaberge et al. (1999) for further details. For the sake of completeness we give a brief outline of this modelling framework.

To account for the fact that single individuals and married couples may face different choice sets and exhibit different preferences over income and leisure we estimate separate models for single females and males and married couples.

\section{A.1. Single females and males}

The utility functions for single females and males is assumed to be of the following form

$$
U(f(w h, I), h, s)=v(h, w, s) \mathcal{E}
$$

where

$w=$ wage rate

$h=$ hours of work

$I=$ exogenous income

$s=1$ if the job belongs to the Public Sector (= 0 otherwise),

$f(w h, I)$ is disposable income (income after tax) measured in 100000 NOK

and $\varepsilon$ follows a Type III extreme value distribution.

The systematic part is specified as follows

$$
\begin{aligned}
& \log (v(h, w, s))=\alpha_{2}\left(\frac{f(w h, I)^{\alpha_{1}}-1}{\alpha_{1}}\right) \\
& +\left(\alpha_{4}+\alpha_{5} \log A+\alpha_{6}(\log A)^{2}+\alpha_{7} s+\alpha_{8} C_{1}+\alpha_{9} C_{2}+\alpha_{10} C_{3}+\alpha_{11} s C_{1}+\alpha_{12} s C_{2}+\alpha_{13} s C_{3}\right)\left(\frac{L^{\alpha_{3}}-1}{\alpha_{3}}\right)
\end{aligned}
$$

where

$L$ is leisure, defined as $L=1-(h / 8736)$, 
$A$ is age,

$C_{1}, C_{2}$, and $C_{3}$ are number of children below 3 , between 3 and 6 and between 7 and 14 years old, respectively.

The $\alpha$-parameters are gender-specific.

The children terms are dropped in the utility function for single males since we observe very few children living with single males.

The stochastic component $\varepsilon$ is assumed to be independently drawn from a Type IIII extreme value distribution.

The individuals maximize their utility by choosing among opportunities defined by hours of work, hourly wage and sector of employment. Opportunities with $h=0$ (and $w=0$ ) are non-market opportunities (i.e. alternative allocations of "leisure").

We write the density of opportunities in sector s requiring $h$ hours of work and paying hourly wage $w$

$$
p(h, w, s)=\left\{\begin{array}{ccc}
p_{0} g_{1 s}(h) g_{2 s}(w) g_{3}(s) & \text { if } & h>0 \\
1-p_{0} & \text { if } & h=0
\end{array}\right.
$$

where $p_{0}$ is the proportion of market opportunities in the opportunity set, $g_{1 \mathrm{~s},} g_{2 \mathrm{~s}}$ and $g_{3}$ are respectively the densities of hours, wages, and opportunities in sector $S$, conditional upon the opportunity being a market job.

Given the above assumption upon the stochastic component and upon the density of opportunities, it turns out that the probability (density) that an opportunity $(h, w, s)$ is chosen is

$$
\varphi(h, w, s)=\frac{v(h, w, s) p(h, w, s)}{\sum_{s=0,1} \iint v(x, y, s) p(x, y, s) d x d y} .
$$

In view of the empirical specification it is convenient to divide both numerator and denominator by $1-p_{0}$ and define $g_{0}=\frac{p_{0}}{1-p_{0}}$. We can then rewrite the choice density as follows:

$$
\varphi(h, w, s)=\frac{v(h, w, s) g_{0} g_{1 s}(h) g_{2 s}(w) g_{3}(s)}{v(0,0,0)+\sum_{s=0,1} \int_{x>0} \int_{y>0} v(x, y, s) g_{0} g_{1 S}(h) g_{2 S}(w) g_{3}(s) d x d y}
$$

for $\{h, w\}>0$ and 


$$
\varphi(0,0,0)=\frac{v(0,0,0)}{v(0,0,0)+\sum_{s=0,1} \int_{x>0} \int_{y>0} v(x, y, s) g_{0} g_{1 s}(h) g_{2 s}(w) g_{3}(s) d x d y}
$$

for $\{h, w\}=0$.

Except for possible peaks corresponding to part time ( $p t, 18-20$ weekly hours) and to full time ( $f t, 37-40$ weekly hours) we assume that the distribution of offered hours is uniformly distributed. Thus, $g_{1}$ is given by

$$
g_{1 s}(h)=\left\{\begin{array}{lcc}
\gamma_{s} & \text { if } & h \in[1,17] \\
\gamma_{s} \exp \left(\pi_{1}+\pi_{2} s\right) & \text { if } & h \in[18,20] \\
\gamma_{s} & \text { if } & h \in[21,36] \\
\gamma_{3} \operatorname{xp}\left(\pi_{3}+\pi_{4} s\right) & \text { if } & h \in[37,40] \\
\gamma_{s} & \text { if } & h \in[41, \omega]
\end{array}\right.
$$

where $\omega$ is the maximum observed value of $h$.

Since the density values must add up to 1 , we can also compute $\gamma_{s}$ according to:

$$
\left.\gamma_{s}((17-1)+(20-18)) \exp \left(\pi_{1}+\pi_{2} s\right)+(36-21)+(40-37) \exp \left(\pi_{3}+\pi_{4} s\right)+(\omega-41)\right)=1
$$

We also specify:

$$
g_{0} g_{3}(s)=\exp \left(\mu_{1} s+\mu_{2}(1-s)\right)
$$

The above parameters $\pi$ and $\mu$ vary by gender. In the tables we refer to $\pi$ and $\mu$ as the parameters of the job opportunity density.

The density of offered wages is assumed to be lognormal with mean that depends on length of schooling $(E d)$ and on past potential working experience (Exp), where experience is defined to be equal to age minus length of schooling minus five, i.e.

$$
\log w=\beta_{0}+\beta_{1} \operatorname{Exp}+\beta_{2} \operatorname{Exp}^{2}+\beta_{3} E d+\sigma \eta
$$

where $\eta$ is standard normally distributed. The parameters $\beta$ vary by gender and sector of employment.

The estimation of the models for single individuals and married couples is based on data from the 1995 Survey of Level of Living. We have restricted the ages of the individuals to be between 
18 and 54 in order to minimize the inclusion in the sample of individuals who in principle are eligible for retirement, since analysis of retirement decisions is beyond the scope of this study. Table A4 reports incomes, participation rates and hours of work observed in the sample.

The parameters appearing in expressions (A1)-(A5) are assumed to differ for single females and males. However, since the opportunity distributions (A3) and (A7)-(A9) concern married males and married females as well, the parameters of the separate utility functions and joint opportunity densities are estimated simultaneously by the method of maximum likelihood. The likelihood function is equal to the products of the labour supply densities for single females, single males and couples. The estimates of opportunity density parameters are reported in Table A3, whilst the preference parameters for single females and males and couples are reported in Tables A1 and A2, respectively.

Table A1. Estimates of the parameters of the utility functions for single females and males. Norway 1994

\begin{tabular}{|c|c|c|c|c|c|}
\hline \multirow{2}{*}{ Variable } & \multirow{2}{*}{ Parameter } & \multicolumn{2}{|c|}{ Single females } & \multicolumn{2}{|c|}{ Single males } \\
\hline & & Estimate & Std. Dev. & Estimate & Std. Dev. \\
\hline \multicolumn{6}{|l|}{ Consumption } \\
\hline & $\alpha_{1}$ & -0.59 & 0.28 & 0.24 & 0.33 \\
\hline & $\alpha_{2}$ & 4.37 & 0.52 & 2.27 & 0.44 \\
\hline \multicolumn{6}{|l|}{ Leisure } \\
\hline & $\alpha_{3}$ & 0.65 & 0.92 & 0.76 & 0.99 \\
\hline & $\alpha_{4}$ & 498.50 & 145.18 & 337.40 & 128.84 \\
\hline Log age & $\alpha_{5}$ & -265.77 & 79.22 & -180.89 & 70.63 \\
\hline Log age squared & $\alpha_{6}$ & 36.36 & 10.89 & 24.81 & 9.75 \\
\hline \# children, $0-2$ years old & $\alpha_{7}$ & 3.62 & 2.43 & & \\
\hline \# children, $3-6$ years old & $\alpha_{8}$ & -0.36 & 7.87 & & \\
\hline \# children, 7 - 14 years old & $\alpha_{9}$ & -2.24 & 1.42 & & \\
\hline Employed in public sector & $\alpha_{10}$ & -2.97 & 0.87 & -2.20 & 0.90 \\
\hline $\begin{array}{l}(\text { Empl. in pub. sec. })(\# \text { child., } \\
0-2 \text { years old })\end{array}$ & $\alpha_{11}$ & -7.29 & 7.46 & & \\
\hline $\begin{array}{l}(\text { Empl. in pub. sec.)(\# child., } \\
3-6 \text { years old })\end{array}$ & $\alpha_{12}$ & -1.02 & 2.10 & & \\
\hline $\begin{array}{l}(\text { Empl. in pub. sec.)(\# child., } \\
7-14 \text { years old })\end{array}$ & $\alpha_{13}$ & 1.15 & 1.10 & & \\
\hline
\end{tabular}




\section{A2. Married couples}

The labour supply model for married couples accounts for both spouses' decisions through the following specification of the structural part of the utility function for couples

(A10)

$$
\begin{aligned}
& \log v\left(h_{M}, h_{F}, w_{M}, w_{F}, s_{M}, s_{F}\right)=\alpha_{2}\left(\frac{f\left(w_{F} h_{F}, w_{M} h_{M}, I\right)^{\alpha_{1}}-1}{\alpha_{1}}\right) \\
& +\left(\alpha_{4}+\alpha_{5} \log A_{F}+\alpha_{6}\left(\log A_{F}\right)^{2}+\alpha_{7} s_{F}+\alpha_{8} C_{1}+\alpha_{9} C_{2}+\alpha_{10} C_{3}+\alpha_{11} s_{F} C_{1}+\alpha_{12} s_{F} C_{2}+\alpha_{13} s_{F} C_{3}\right)\left(\frac{L_{F}^{\alpha_{14}}-1}{\alpha_{14}}\right) \\
& +\left(\alpha_{15}+\alpha_{16} \log A_{M}+\alpha_{17}\left(\log A_{M}\right)^{2}+\alpha_{18} s_{M}+\alpha_{19} C_{1}+\alpha_{20} C_{2}+\alpha_{21} C_{3}+\alpha_{22} s_{M} C_{1}+\alpha_{23} s_{M} C_{2}+\alpha_{24} s_{M} C_{3}\right)\left(\frac{L_{M}^{\alpha_{3}}-1}{\alpha_{3}}\right) \\
& +\alpha_{25}\left(\frac{L_{M}^{\alpha_{3}}-1}{\alpha_{3}}\right)\left(\frac{L_{F}^{\alpha_{14}}-1}{\alpha_{14}}\right) .
\end{aligned}
$$

where the leisure $L_{i}$ is defined as $L_{i}=1-\left(h_{i} / 8736\right), i=F, M$. We allow for sector- and genderspecific job opportunities in accordance with the functional forms ((A2)-(A6)) that were used for single females and males.

In this case the households choose among opportunities defined by a vector $\left(h_{M}, h_{F}, w_{M}, w_{F}, s_{M}, s_{F}\right)$. Here $S_{k}=1$ if the partner of gender k is employed in the public sector, with $\mathrm{k}=\mathrm{M}, \mathrm{F}$. Analogously to what we have done with singles, we specify the corresponding density function as

$$
p\left(h_{M}, h_{F}, w_{M}, w_{F}, s_{M}, s_{F}\right)= \begin{cases}p_{0 M} g_{1 s_{M}}\left(h_{M}\right) g_{2 s_{M}}\left(w_{M}\right) g_{3}\left(s_{M}\right) p_{0 F} g_{1 s_{F}}\left(h_{F}\right) g_{2 s_{F}}\left(w_{F}\right) g_{3}\left(s_{F}\right) & \text { if } h_{M}>0, h_{F}>0 \\ p_{0 M} g_{1 s_{M}}\left(h_{M}\right) g_{2 s_{M}}\left(w_{M}\right) g_{3}\left(s_{M}\right)\left(1-p_{0 F}\right) & \text { if } h_{M}>0, h_{F}=0 \\ \left(1-p_{0 M}\right) p_{0 F} g_{1 s_{F}}\left(h_{F}\right) g_{2 s_{F}}\left(w_{F}\right) g_{3}\left(s_{F}\right) & \text { if } h_{M}=0, h_{F}>0 \\ \left(1-p_{0 M}\right)\left(1-p_{0 F}\right) & \text { if } h_{M}=0, h_{F}>0\end{cases}
$$

The choice density of an opportunity $\left(h_{M}, h_{F}, w_{M}, w_{F}, s_{M}, s_{F}\right)$ is:

(A12)

$$
\varphi\left(h_{M}, h_{F}, w_{M}, w_{F}, s_{M}, s_{F}\right)=\frac{v\left(h_{M}, h_{F}, w_{M}, w_{F}, s_{M}, s_{F}\right) p\left(h_{M}, h_{F}, w_{M}, w_{F}, s_{M}, s_{F}\right)}{\sum_{s_{M}=0,10} \sum_{s_{F}=0,1} \iiint \int v\left(x_{M}, x_{F}, y_{M}, y_{F}, s_{M}, s_{F}\right) p\left(x_{M}, x_{F}, y_{M}, y_{F}, s_{M}, s_{F}\right) d x_{M} d y_{F} d x_{M} d y_{M}}
$$


For the purpose of empirical specification and estimation it is convenient to divide the density $p($ ) by $\left(1-p_{0 M}\right)\left(1-p_{0 F}\right)$ and define

$$
\begin{aligned}
& g_{0 M}=\frac{p_{0 M}}{\left(1-p_{0 M}\right)} \\
& g_{0 F}=\frac{p_{0 F}}{\left(1-p_{0 F}\right)} \\
& g_{0 M F}=\frac{p_{0 M} p_{0 F}}{\left(1-p_{0 M}\right)\left(1-p_{0 F}\right)}
\end{aligned}
$$

Now the choice density can be written as follows:

(A14)

$\varphi\left(h_{M}, h_{F}, w_{M}, w_{F}, s_{M}, s_{F}\right)=\frac{v\left(h_{M}, h_{F}, w_{M}, w_{F}, s_{M}, s_{F}\right) g_{0 M F} g_{1 s_{M}}\left(h_{M}\right) g_{2 s_{M}}\left(w_{M}\right) g_{3}\left(s_{M}\right) g_{1 s_{F}}\left(h_{F}\right) g_{2 s_{F}}\left(w_{F}\right) g_{3}\left(s_{F}\right)}{D}$

if both work;

$$
\varphi\left(h_{M}, 0, w_{M}, 0, s_{M}, 0\right)=\frac{v\left(h_{M}, 0, w_{M}, 0, s_{M}, 0\right) g_{0 M} g_{1 s_{M}}\left(h_{M}\right) g_{2 s_{M}}\left(w_{M}\right) g_{3}\left(s_{M}\right)}{D}
$$

if only the husband works;

$$
\varphi\left(0, h_{F}, 0, w_{F}, 0, s_{F}\right)=\frac{v\left(0, h_{F}, 0, w_{F}, 0, s_{F}\right) g_{0 F} g_{1 s_{F}}\left(h_{F}\right) g_{2 s_{F}}\left(w_{F}\right) g_{3}\left(s_{F}\right)}{D}
$$

if only the wife works;

$$
\varphi(0,0,0,0,0,0)=\frac{v(0,0,0,0,0,0)}{D}
$$

if none of them work, where we have defined 
(A18)

$D=v(0,0,0,0,0,0)$

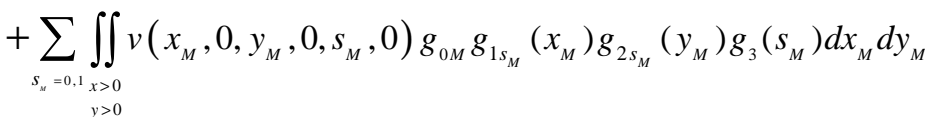

$+\sum_{s_{\mu}=0,1} \iint_{x>0} v\left(0, x_{F}, 0, y_{F}, 0, s_{F}\right) g_{0 F} g_{1 s_{F}}\left(x_{F}\right) g_{2 s_{F}}\left(y_{F}\right) g_{3}\left(s_{F}\right) d x_{F} d y_{F}$

$+\sum_{s_{\alpha}=0,1 s_{r}=0,1} \iiint_{\int_{x>0}} v\left(x_{M}, x_{F}, y_{M}, y_{F}, s_{M}, s_{F}\right) g_{0 M F} g_{1 s_{M}}\left(x_{M}\right) g_{2 s_{M}}\left(y_{M}\right) g_{3}\left(s_{M}\right) p_{0 F} g_{1 s_{F}}\left(x_{F}\right) g_{2 s_{F}}\left(y_{F}\right) g_{3}\left(s_{F}\right) d x_{M} d y_{F} d x_{M} d y_{M}$

The hour densities and the wage densities are the same as specified for singles. The same applies to $g_{0 M} g_{3}\left(s_{M}\right)$ and $g_{0 F} g_{3}\left(s_{F}\right)$. Moreover:

(A19)

$$
g_{0 M F} g_{3}\left(s_{M}\right) g_{3}\left(s_{F}\right)=\exp \left(\mu_{0}+\mu_{1 M}\left(s_{M}\right)+\mu_{2 M}\left(1-s_{M}\right)+\mu_{1 F}\left(s_{F}\right)+\mu_{2 F}\left(1-s_{F}\right)\right) .
$$

The estimates of the preference parameters for couples are reported in Table A2. 
Table A2. Estimates of the parameters of the utility function for married/cohabitating couples. Norway 1994

\begin{tabular}{|c|c|c|c|}
\hline Variable & Parameter & Estimate & Std. Dev. \\
\hline \multicolumn{4}{|l|}{ Consumption } \\
\hline & $\alpha_{1}$ & 0.14 & $(0.09)$ \\
\hline & $\alpha_{2}$ & 6.49 & $(0.43)$ \\
\hline \multicolumn{4}{|l|}{ Wife's leisure } \\
\hline & $\alpha_{3}$ & -3.81 & $(0.43)$ \\
\hline & $\alpha_{4}$ & 194.89 & $(28.53)$ \\
\hline Log age & $\alpha_{5}$ & -107.09 & $(15.88)$ \\
\hline Log age squared & $\alpha_{6}$ & 15.14 & $(2.23)$ \\
\hline \# children, $0-2$ years old & $\alpha_{7}$ & 0.34 & $(0.31)$ \\
\hline \# children, $3-6$ years old & $\alpha_{8}$ & 1.31 & $(0.31)$ \\
\hline \# children, 7 - 14 years old & $\alpha_{9}$ & 1.70 & $(0.26)$ \\
\hline Employed in public sector & $\alpha_{10}$ & -0.95 & $(0.30)$ \\
\hline (Empl. in pub. sec.)(\# child., $0-2$ years old) & $\alpha_{11}$ & 0.40 & $(0.33)$ \\
\hline (Empl. in pub. sec.)(\# child., $3-6$ years old) & $\alpha_{12}$ & 0.39 & $(0.32)$ \\
\hline (Empl. in pub. sec.)(\# child., 7 - 14 years old) & $\alpha_{13}$ & -0.97 & $(0.24)$ \\
\hline \multicolumn{4}{|l|}{ Husband's leisure } \\
\hline & $\alpha_{14}$ & -1.01 & (039) \\
\hline & $\alpha_{15}$ & 222.99 & $(41.03)$ \\
\hline Log age & $\alpha_{16}$ & -116.55 & $(22.34)$ \\
\hline Log age squared & $\alpha_{17}$ & 15.85 & $(3.06)$ \\
\hline \# children, $0-2$ years old & $\alpha_{18}$ & -0.08 & $(0.40)$ \\
\hline \# children, 3 - 6 years old & $\alpha_{19}$ & -0.30 & $(0.35)$ \\
\hline \# children, 7 - 14 years old & $\alpha_{20}$ & -0.15 & $(0.25)$ \\
\hline Employed in public sector & $\alpha_{21}$ & -0.60 & $(0.51)$ \\
\hline (Empl. in pub. sec.)(\# child., $0-2$ years old) & $\alpha_{22}$ & -0.16 & $(0.39)$ \\
\hline (Empl. in pub. sec.)(\# child., 3 - 6 years old) & $\alpha_{23}$ & -0.93 & $(0.31)$ \\
\hline (Empl. in pub. sec.)(\# child., 7 - 14 years old) & $\alpha_{24}$ & -0.16 & $(0.25)$ \\
\hline Leisure interaction between spouses & $\alpha_{25}$ & 4.84 & $(1.12)$ \\
\hline
\end{tabular}

\footnotetext{
*) Standard deviations in parentheses.
} 
Table A3. Job, Hours and Wage densities, Norway 1994

\begin{tabular}{|c|c|c|c|c|c|}
\hline & \multirow{2}{*}{ Parameter } & \multicolumn{2}{|c|}{ Females } & \multicolumn{2}{|c|}{ Males } \\
\hline & & Estimate & Std. Dev. & Estimate & Std. Dev. \\
\hline \multirow{3}{*}{ Job opportunity } & $\mu_{1}$ & -2.10 & $(0.18)$ & -3.17 & $(0.23)$ \\
\hline & $\mu_{2}$ & -1.51 & $(0.18)$ & -2.68 & $(0.20)$ \\
\hline & $\mu_{3}$ & 1.39 & $(0.17)$ & 1.39 & $(0.17)$ \\
\hline \multirow{4}{*}{ Hours } & $\pi_{1}$ & 0.49 & $(0.13)$ & -0.50 & $(0.22)$ \\
\hline & $\pi_{2}$ & -0.23 & $(0.23)$ & 0.09 & $(0.51)$ \\
\hline & $\pi_{3}$ & 1.47 & $(0.09)$ & 1.81 & $(0.07)$ \\
\hline & $\pi_{4}$ & 0.03 & $(0.14)$ & 0.06 & $(0.13)$ \\
\hline \multirow{5}{*}{ Wage - Private sector } & $\beta_{0}$ & 3.62 & $(0.07)$ & 3.50 & $(0.06)$ \\
\hline & $\beta_{1}$ & 3.93 & $(0.50)$ & 5.38 & $(0.41)$ \\
\hline & $\beta_{2}$ & 2.60 & $(0.30)$ & 2.83 & $(0.31)$ \\
\hline & $\beta_{3}$ & -4.04 & $(0.64)$ & -4.41 & $(0.64)$ \\
\hline & $\sigma$ & 0.24 & $(0.00)$ & 0.28 & $(0.01)$ \\
\hline \multirow{5}{*}{ Wage - Public sector } & $\beta_{0}$ & 3.71 & $(0.08)$ & 3.62 & $(0.09)$ \\
\hline & $\beta_{1}$ & 3.59 & $(0.46)$ & 4.95 & $(0.47)$ \\
\hline & $\beta_{2}$ & 2.14 & $(0.33)$ & 2.46 & $(0.44)$ \\
\hline & $\beta_{3}$ & -3.37 & $(0.71)$ & -3.82 & $(0.91)$ \\
\hline & $\sigma$ & 0.18 & $(0.01)$ & 0.22 & 0.01 \\
\hline
\end{tabular}


Table A4. Incomes and labour supply under the current tax rule, Norway 1994

\begin{tabular}{|c|c|c|c|c|c|c|c|c|c|c|}
\hline \multirow{3}{*}{ Family status } & \multirow{3}{*}{$\begin{array}{c}\text { Household } \\
\text { income } \\
\text { decile }\end{array}$} & \multirow{2}{*}{\multicolumn{2}{|c|}{$\begin{array}{c}\text { Participation rates } \\
\text { (Per cent) }\end{array}$}} & \multicolumn{4}{|c|}{ Annual hours } & \multicolumn{3}{|c|}{ Household income, NOK 1994} \\
\hline & & & & \multicolumn{2}{|c|}{ Given participation } & \multicolumn{2}{|c|}{ In the total population } & \multirow{2}{*}{ Gross income } & \multirow{2}{*}{ Taxes } & \multirow{2}{*}{$\begin{array}{c}\text { Disposable } \\
\text { income }\end{array}$} \\
\hline & & M & $\mathrm{F}$ & $\mathrm{M}$ & $\mathrm{F}$ & $\mathrm{M}$ & $\mathrm{F}$ & & & \\
\hline \multirow{6}{*}{ Single males (M) } & I & 58 & & 1271 & & 738 & & 82300 & 11496 & 70804 \\
\hline & II & 84 & & 1340 & & 1124 & & 105212 & 18564 & 86648 \\
\hline & III-VIII & 89 & & 2040 & & 1812 & & 185304 & 44527 & 140778 \\
\hline & IX & 97 & & 2218 & & 2147 & & 306905 & 92142 & 214762 \\
\hline & $\mathrm{X}$ & 77 & & 2739 & & 2120 & & 462074 & 158374 & 303700 \\
\hline & All & 85 & & 2003 & & 1701 & & 206694 & 54708 & 151986 \\
\hline \multirow{6}{*}{ Single females (F) } & I & & 55 & & 1144 & & 627 & 83684 & 10033 & 73652 \\
\hline & II & & 71 & & 1346 & & 955 & 105927 & 14191 & 91737 \\
\hline & III-VIII & & 84 & & 1782 & & 1503 & 176901 & 37575 & 139326 \\
\hline & IX & & 94 & & 2026 & & 1895 & 261767 & 61129 & 200638 \\
\hline & $\mathrm{X}$ & & 97 & & 2723 & & 2636 & 323771 & 79917 & 243855 \\
\hline & All & & 82 & & 1841 & & 1513 & 183677 & 39077 & 144601 \\
\hline \multirow{6}{*}{ Couples } & I & 72 & 58 & 1433 & 1100 & 1036 & 640 & 189680 & 32180 & 157500 \\
\hline & II & 76 & 78 & 1624 & 1239 & 1227 & 963 & 257300 & 50697 & 206603 \\
\hline & III-VIII & 92 & 86 & 2016 & 1517 & 1846 & 1304 & 399046 & 102457 & 296590 \\
\hline & IX & 95 & 93 & 2376 & 1750 & 2259 & 1626 & 580544 & 174194 & 406350 \\
\hline & $\mathrm{X}$ & 86 & 81 & 2583 & 1742 & 2232 & 1411 & 828424 & 258943 & 569481 \\
\hline & I-X & 88 & 83 & 2029 & 1510 & 1783 & 1246 & 424994 & 113064 & 311931 \\
\hline
\end{tabular}

